\title{
Revision of Begomovirus taxonomy based on pairwise sequence comparisons
}

\author{
Judith K. Brown ${ }^{1}$ F. Murilo Zerbini ${ }^{2,3} \cdot$ Jesús Navas-Castillo $^{2,3,4} \cdot$ Enrique Moriones $^{4}$. \\ Roberto Ramos-Sobrinho $^{2,3}$ - José C. F. Silva ${ }^{3}$ - Elvira Fiallo-Olivé, , $, 3,4^{2}$ Rob W. Briddon ${ }^{5}$. \\ Cecilia Hernández-Zepeda ${ }^{6}$ - Ali Idris ${ }^{7}$ V. G. Malathi ${ }^{8} \cdot$ Darren P. Martinn $^{9}$ \\ Rafael Rivera-Bustamante $^{10} \cdot$ Shigenori Ueda $^{11} \cdot$ Arvind Varsani $^{12,13,14}$
}

Accepted: 9 March 2015/Published online: 18 April 2015

(C) Springer-Verlag Wien 2015

\begin{abstract}
Viruses of the genus Begomovirus (family Geminiviridae) are emergent pathogens of crops throughout the tropical and subtropical regions of the world. By virtue of having a small DNA genome that is easily cloned, and due to the recent innovations in cloning and low-cost sequencing, there has been a dramatic increase in the number of available begomovirus genome sequences. Even so, most of the available sequences have been obtained from cultivated plants and are likely a small and phylogenetically unrepresentative sample of begomovirus diversity, a factor constraining taxonomic decisions such as the establishment of operationally useful species demarcation criteria. In addition, problems in assigning new viruses to established species have highlighted
\end{abstract}

Electronic supplementary material The online version of this article (doi:10.1007/s00705-015-2398-y) contains supplementary material, which is available to authorized users.

Judith K. Brown

jbrown@ag.arizona.edu

$凶$ F. Murilo Zerbini

zerbini@ufv.br

1 School of Plant Sciences, University of Arizona, Tucson, AZ 85721, USA

2 Dep. de Fitopatologia/BIOAGRO, Universidade Federal de Viçosa, Viçosa, MG 36570-900, Brazil

3 National Research Institute for Plant-Pest Interactions (INCT-IPP), Universidade Federal de Viçosa, Viçosa, MG 36570-900, Brazil

4 Instituto de Hortofruticultura Subtropical y Mediterránea, "La Mayora", Universidad de Málaga-Consejo Superior de Investigaciones Científicas (IHSM-UMA-CSIC), 29750 Algarrobo-Costa, Málaga, Spain

5 National Institute for Biotechnology and Genetic Engineering, Jhang Road, P.O. Box 577, Faisalabad, Pakistan shortcomings in the previously recommended mechanism of species demarcation. Based on the analysis of 3,123 fulllength begomovirus genome (or DNA-A component) sequences available in public databases as of December 2012, a set of revised guidelines for the classification and nomenclature of begomoviruses are proposed. The guidelines primarily consider a) genus-level biological characteristics and b) results obtained using a standardized classification tool, Sequence Demarcation Tool, which performs pairwise sequence alignments and identity calculations. These guidelines are consistent with the recently published recommendations for the genera Mastrevirus and Curtovirus of the family Geminiviridae. Genome-wide pairwise identities of $91 \%$ and $94 \%$ are proposed as the demarcation threshold for begomoviruses belonging to different species and strains, respectively. Procedures and

6 Centro de Investigación Científica de Yucatán, Unidad de Ciencias del Agua, Cancún, Quintana Roo, Mexico

7 Division of Biological and Environmental Sciences and Engineering, Center for Desert Agriculture, King Abdullah University of Science and Technology, Thuwal 23955-6900, Saudi Arabia

8 Department of Plant Pathology, Adjunct Faculty, Tamil Nadu Agricultural University, Coimbatore 641003, India

9 Computational Biology Group, Institute of Infectious Diseases and Molecular Medicine, University of Cape Town, Cape Town, South Africa

10 Departamento de Ingeniería Genética, Centro de Investigación y de Estudios Avanzados del IPN (Cinvestav)Unidad Irapuato, 36821 Irapuato, GTO, Mexico

11 Kurume Research Station, National Agricultural Research, Center for Kyushu Okinawa Region, 1823 Mii, Kurume, Fukuoka 839-8503, Japan 
guidelines are outlined for resolving conflicts that may arise when assigning species and strains to categories wherever the pairwise identity falls on or very near the demarcation threshold value.

Keywords Geminiviridae - Nomenclature - Sequence Demarcation Tool - Single-stranded DNA virus - Species demarcation · Taxonomy · Whitefly-transmitted viruses

\section{Introduction}

The genus Begomovirus (family Geminiviridae) is the largest genus of plant viruses with respect to the number of species that it includes. In fact, with 288 species currently recognized by the International Committee on Taxonomy of Viruses (ICTV) (http://www.ictvonline.org/virusTaxonomy. asp), it is the largest genus of all viral taxonomy. Begomoviruses infect a wide range of dicotyledonous plants, mostly in tropical and subtropical regions of the world. Their circular, single-stranded DNA genomes can be either monopartite or bipartite (with genomic components known as DNA-A and DNA-B), with the two components of bipartite genomes sharing a common region of approximately 200 nucleotides that includes the origin of replication [1]. In the Old World (OW; Africa, Asia, Australasia and Europe), most begomoviruses are monopartite, with a few having a bipartite genome. Begomoviruses native to the New World (NW; the Americas) are almost exclusively bipartite, with only a single monopartite virus having been identified so far $[2,3]$. However, a number of monopartite begomoviruses occur in the NW as a result of their recent introduction from the OW $[4,5]$.

Geminiviruses have characteristically twinned or "geminate" particle morphology. The capsid consists of two joined, incomplete $\mathrm{T}=1$ icosahedral heads, with 110 molecules of the capsid protein organized as 22 pentameric capsomers [6]. Geminate particles contain a single molecule of circular ssDNA that ranges from 2.5 to 3.0 kilobases $(\mathrm{kb})$ [1]. Therefore, for viruses having a bipartite genome, two particles, each containing a different genomic component (DNA-A and DNA-B), are required to establish infection.

Due to their economic importance as plant pathogens and their small genomes, begomoviruses were among the first

12 Electron Microscope Unit, University of Cape Town, Rondebosch, Cape Town 7701, South Africa

13 Department of Plant Pathology and Emerging Pathogens Institute, University of Florida, Gainesville, FL 32611, USA

14 School of Biological Sciences, University of Canterbury, Private Bag 4800, Christchurch 8140, New Zealand plant viruses whose complete genomes were cloned and sequenced [7, 8]. By January 2014, more than 3500 fulllength begomovirus sequences had been deposited in public databases. Even during the early days of full-genome sequencing, the increasingly large numbers of begomovirus sequences being determined worldwide made it clear that these viruses are abundant and widespread, and that they display a significant degree of genetic diversity [9]. Also, it created the opportunity for the development of a sequencebased taxonomy that relied primarily on pairwise sequence comparisons [10]. Such a system has been in place for the Geminiviridae since the mid-1990s, and it has been remarkably stable. It was also widely embraced by the begomovirus community, mostly due to its simplicity and ease of use. Similar classification systems have been adopted by a number of ICTV study groups, including those concerned with the Anelloviridae and the Circoviridae.

As useful as it has been to establish and streamline taxonomic communications, begomovirus taxonomy is not without controversy. Several criticisms have been voiced in the literature (one recent example being ref. [11]) and by the ICTV Executive Committee (EC), which rejected the Geminiviridae Study Group's taxonomic proposals for creating new begomovirus species in 2010 and 2011. The main points of contention can be summarized as follows: (i) the creation of "too many" species in the genus; (ii) the recognition of new species based solely on sequence comparisons of members, without taking into consideration the biological properties of the viruses; and (iii) the establishment of species demarcation criteria that were "too relaxed" compared to those for other genera in the family, thus leading to point $i$. Moreover, and as pointed out by the Geminiviridae Study Group (SG) itself in the recent Mastrevirus and Curtovirus taxonomy revisions [12, 13], pairwise sequence identities for any particular pair of sequences may be calculated in different ways and therefore can result in differences in identity scores depending on the algorithm employed. Such discrepancies have made it highly desirable to establish a standard procedure to perform pairwise alignments and to calculate identity scores in order to eliminate (or at least minimize) taxonomic uncertainties and/or misplacements.

The concerns raised by the ICTV EC regarding begomovirus taxonomy encouraged the Geminiviridae SG to perform a comprehensive re-evaluation of the species demarcation criteria for the genus Begomovirus. The results of this re-evaluation have demonstrated that the current pairwise-identity-based taxonomy is sound, that it accurately reflects the biology of begomoviruses, that it will be stable, and that it will be easy to understand and to be adopted by geminivirologists worldwide. Here, we present the specific guidelines for the classification of begomoviruses, following those recently published for the 
genera Mastrevirus [12] and Curtovirus [13] of the family Geminiviridae.

\section{A comprehensive analysis of the species demarcation criteria for the begomoviruses}

Since a significant proportion of begomoviruses do not have a cognate DNA-B component, this component is not considered for species demarcation. A total of 3,123 full-length begomovirus genomic sequences (or DNA-A sequences) were downloaded from the NCBI-GenBank database on 31 Dec 2012. They corresponded to viruses belonging to 283 species according to the currently accepted $89 \%$ species demarcation criterion (for comparison, see the 9th Report of the ICTV, which lists 192 species in the genus [1]). To reduce computing time, only the oldest sequences (full-length genomes or DNA-A components) from groups of sequences that shared $>99.5 \%$ genome-wide nucleotide (nt) sequence identity were included in the analysis. To the best of our knowledge, the analysis included sequences of members of all ICTV-recognized species and unclassified begomoviruses for which at least one full-length sequence was available in GenBank at that time (for many, there were multiple sequences per virus/strain). Using this data set $(1,826$ sequences), a preliminary phylogeny using the neighbor-joining (NJ) method was constructed (data not shown). The purpose of the NJ phylogenetic analysis was not to construct a definitive phylogeny but rather to identify groups of most closely related sequences that could be combined for pairwise sequence comparisons and maximum-likelihood (ML) phylogenetic analyses.

Based on the NJ phylogenetic tree, 38 groups were identified, each of which contained sequences that did not obviously correspond to the same viral species but also did not obviously correspond to distinct species. This approach was employed to more easily delineate distinct groups. Some groups consisted of as few as 2-3 sequences, whereas, others were represented by $>30$ sequences (Supplementary File S1). Pairwise sequence comparisons were carried out separately for each one of the 38 groups, using Sequence Demarcation Tool (SDT) v. 1.0 [14] with the MUSCLE [15] alignment option. Also, ML phylogenetic trees were predicted for each group using the PHYML3.0 method implemented in MEGA 5.2 [16] with the GTR $+\mathrm{I}+\mathrm{G}$ nucleotide (nt) substitution model and branch support being tested with 3,000 bootstrap iterations.

Simulations were performed based on the results of pairwise sequence comparisons, using different cutoff values (rounded to the nearest full percentile) to delineate potential species so as to determine which sequences corresponded to virus isolates belonging to the same species, and which were isolates of distinct species. For this, we looked for the optimum cutoff value that placed each sequence into a given species without "outliers" (sequences that displayed identity levels above the cutoff value with two or more species).

Analysis of all 38 groups indicated that the best nt sequence identity cutoff value to separate isolates from different species was $91 \%$. This value is proposed here as the new species demarcation criterion for viruses of the genus Begomovirus using the outlined methodology. Implementing this value yielded the lowest number of outlier sequences compared to any other value within the range of $86 \%$ to $94 \%$ nt sequence identity. The cutoff for strain demarcation is $94 \%$. Parameters used for comparison are crucial. It is important to note that percent nt sequence identities must be calculated from true pairwise sequence alignments, with the exclusion of sites with gap characters. Ideally, the SDT software that is freely available [14] (http://web.cbio.uct.ac.za/SDT) should be used, as it was developed specifically for this purpose.

Phylogenetic support was found to be robust for all new species analyzed across the 38 groups. The $91 \%$ cutoff value is actually quite conservative, as is indicated by the trees for groups 3, 5, 7, 11, 16, 30 and 33 (Supplementary File S1). However, several groups (1, 2, 6, 27, 34 and 36; Supplementary File S1) required additional consideration because the pairwise sequence comparisons and phylogenetic results are conflicting, possibly due to recombination.

\section{Dealing with outliers}

The resulting taxonomic framework resulted in the delineation of a small number of outliers. Nevertheless, as the number of sequenced begomoviral genomes continues to increase, additional "conflicting" sequences will become evident. To address this problem, we propose the adoption of the approach described for viruses of the genera Mastrevirus [12] and Curtovirus [13]. In this light, the four possible conflicts are as follows:

1. An isolate having $\geq 91 \%$ identity (full-length genome or DNA-A component) to isolates assigned to two (or more) species.

2. An isolate having $\geq 91 \%$ identity to one or a few isolates from a particular species, even though it shares $<91 \%$ identity with the majority of isolates in that species.

3. An isolate having $\geq 94 \%$ identity to isolates of two (or more) strains of a given species.

4. An isolate having $\geq 94 \%$ identity to one or a few isolates from a particular strain, even though it shares 
$<94 \%$ identity with the majority of isolates from that strain.

The corresponding conflict-resolution criteria are as follows:

1. The new isolate should be considered to belong to the species that includes the isolate with which it shares the highest percentage of pairwise identity (full-length genome or DNA-A component).

2. The new isolate should be classified as belonging to the species with which it shares $\geq 91 \%$ nt sequence identity with any one isolate from that species, even if it is $<91 \%$ identical to all other isolates from that species.

3. The new isolate should be considered to belong to the strain that includes the isolate with which it shares the highest percent identity.

4. The new isolate should be classified as belonging to the strain with which it shares $\geq 94 \%$ nt sequence identity with any one isolate from that strain, even if it has $<94 \%$ identity to all other isolates from that strain.

Naturally, any working cutoff value established for viruses, particularly when rapid divergence is occurring (as appears to be the case for begomoviruses), will yield a number of outliers. By adopting these four conflictresolution criteria, all outliers identified so far could be readily placed into an extant species group.

Exceptions to these rules can include recombinant viruses such as tomato yellow leaf curl Malaga virus (TYLCMaV) and tomato yellow leaf curl Axarquia virus (TYLCAxV), which have $\geq 91 \%$ identity to both parental viruses (tomato yellow leaf curl virus, TYLCV, and tomato yellow leaf curl Sardinia virus, TYLCSV), thus leading to conflict \#1 and causing the two parental species to merge into a single species, even though all isolates of the parental viruses have $<91 \%$ identity. Such recombinant viruses will have to be examined on a case-by-case basis for species assignment.

\section{The new species demarcation criterion of $<91 \% \mathrm{nt}$ sequence identity (for full-length genomes or DNA- A components) is more stringent than the previously used $89 \%$}

At first, the higher value, at $91 \%$, compared to the previously implemented working cutoff of $89 \%$, may give the impression of a more relaxed species demarcation scenario that might delineate an even greater number of begomovirus species. However, this is not the case. Rather, the pairwise cutoff value at $91 \%$ is a consequence of the implementation of a more robust approach (now standardized for the entire family Geminiviridae) for calculating pairwise identities: true pairwise alignments (compared to global alignment-based pairwise identities) without gaps. This proved to be more stringent than previous approaches based on multiple sequence alignments with gaps treated as a fifth character, which yielded a working cutoff of $89 \%$.

One group of begomoviruses that has been affected the most by applying the revised analysis is the "sweepovirus" group, a divergent clade of whitefly-transmitted geminiviruses that infect sweet potato and wild species in the Convolvulaceae. Previously, the group was proposed to include 17 species [17]. The new system reduces the number of species by more than half, delineating 8 species (Table 1; Fig. 1).

\section{Results of pairwise sequence comparisons accurately reflect the biology of begomoviruses}

It has been claimed that begomoviral species are artificial because they are arbitrarily defined based on sequence alone, and therefore their biological characteristics have been ignored [11]. This is a misconception. Sequencebased taxonomy is possible only because it relies on the knowledge of the biological properties of these well-studied viruses. Therefore, sequence comparisons among related begomovirus isolates can accurately reflect differences in their biology. Several examples can be drawn upon to argue this point. One well-known example involves bean golden mosaic disease, an important disease of bean crops in Latin America. The disease is caused by at least two distinct, well-characterized begomoviruses, bean golden mosaic virus (BGMV), which occurs in Brazil and Argentina, and bean golden yellow mosaic virus (BGYMV), which occurs in Central/North America and the Caribbean Basin [18]. The symptoms of the disease are nearly indistinguishable, the whitefly vector species is the same for both pathogens, and the economic importance with respect to crop loss is comparable as well. In fact, initially, the same begomoviral etiology was suspected for the disease occurring in the two regions. However, when the causal agents from plants collected in Puerto Rico (USA) and Brazil were sequenced, the results indicated that they had substantially different genome sequences [19, 20]. Later, it was demonstrated that the two agents differed in at least one relevant biological property: tissue tropism. BGMV is phloem-restricted in beans, while BGYMV is not [20, 21]. Thus, the species cutoff based on sequence alone was accurate and reflected the biological differences between the viruses belonging to these two species. 
Table 1 List of begomovirus species, as of January 2015. Species names are shown in bold italics, and isolate names are given in regular font. For species that do not have any known strains, only one isolate is listed, and that isolate is recognized as the "type" isolate. For species that have known strains, one isolate from each strain is shown, and the type isolate is the first one listed. Sequence accession numbers and assigned abbreviations are also listed. An expanded table including all begomovirus isolates in GenBank is available for download at the ICTV website (talk.ictvonline.org/ictv_wikis/ $\mathrm{m} /$ files_begomo/default.aspx)

\section{Abutilon golden mosaic Yucatan virus}

Abutilon golden mosaic Yucatan virus - [Mexico-Yucatan-2007]

AbGMYV-[MX-Yuc-2007]

KC430935

Abutilon mosaic Bolivia virus

Abutilon mosaic Bolivia virus - [Bolivia-2007]

AbMBoV-[BO-07]

AbMBV-[BR-BgV01A.1.C21]

JF694480

JF694483

Abutilon mosaic Brazil virus - [Brazil-BgV01A.1.C21]

Abutilon mosaic virus

Abutilon mosaic virus - [Germany]

AbMV-[DE]

X15983

ACMV-[CM-98]

AF112352

AF112353

African cassava mosaic virus - [Cameroon-1998]

Ageratum enation virus

Ageratum enation virus - Nepal [Nepal-1999]

Ageratum enation virus - India [India-Kangra-2008]

Ageratum enation virus - Uttar Pradesh [India-Uttar Pradesh-SKS-P-2010]

Ageratum leaf curl virus

Ageratum leaf curl virus - [China-Guangxi 52-2003]

Ageratum yellow vein Sri Lanka virus

Ageratum yellow vein Sri Lanka virus - [Sri Lanka-1999]

Ageratum yellow vein virus

Ageratum yellow vein virus - Guangxi [China-Guangxi 129-2005]

Ageratum yellow vein virus - [Japan-Soybean crinkle leaf]

Ageratum yellow vein virus - China [China-Tomato-2012]

Ageratum yellow vein virus - Hsinchu [Taiwan-Hsinchu-Tom-2003]

Ageratum yellow vein virus - Hualian [Taiwan-Hualian 4-2000]

Ageratum yellow vein virus - Indonesia [Indonesia-Tomato]

Ageratum yellow vein virus - Kamphaengsaen [Thailand-Kamphaengsaen-AFSP3d-2010]

Ageratum yellow vein virus - Nanning [China-Nanning-NN1-2009]

Ageratum yellow vein virus - Philippines [Philippines-Mindanao-2007]

Ageratum yellow vein virus - Singapore [Japan-Ishigaki-2005]

Ageratum yellow vein virus - Taiwan [Taiwan-Tainan-1999]

Ageratum yellow vein virus - Thailand [Thailand-Kamphaengsaen-AFSP6b-2010]

Allamanda leaf curl virus

Allamanda leaf curl virus - [China-Guangdong 10-2006]

Alternanthera yellow vein virus

Alternanthera yellow vein virus - A [China-Fujian 22-2006]

Alternanthera yellow vein virus - B [China-Fujian-PT1-2006]

Bean calico mosaic virus

Bean calico mosaic virus - [Mexico-Sonora-1986]

Bean chlorosis virus

Bean chlorosis virus - [Venezuela-LaBarinesa459-2006]

Bean chlorotic mosaic virus

Bean chlorotic mosaic virus - [Venezuela-Rubio932-2007]

Bean dwarf mosaic virus

Bean dwarf mosaic virus - [Colombia-1987]
AEV-NP[NP-99]

AJ437618

AEV-IN[IN-Kan-08]

FN543099

AEV-UP[IN-UP-Ag10-10]

HM149260

ALCuV-[CN-Gx52-03]

AYVSLV-[LK-99]

AF314144

AYVV-Gx[CN-Gx129-05]

AM940137

AYVV-[JP-Soy]

AB050781

AYVV-CN[CN-Tom-12]

AYVV-Hsi[TW-Hsi-Tom-03]

AYVV-Hua[TW-Hua4-00]

AYVV-ID[ID-Tom]

AYVV-Ka[TH-Ka-AFSP3d-10]

AYVV-NN[CN-Nan-NN1-09]

AYVV-PH[PH-Min-07]

AYVV-SG[JR-Ish-05]

AYVV-TW[TW-Tai-99]

AYVV-TH[TH-Ka-AFSP6b-

10]

AllLCV-A[CN-Gd10-06]

EF602306

AlYVV-A[CN-Fj22-06]

EF544604

AlYVV-B[CN-Fj-PT1-06]

EF544602

BCaMV-[MX-Son-86]

AF110189

AF110190

BChV-[VE-LaB459-06]

JN848770

JN848771

BChMV-[VE-Rub932-07]

JN848772

JN848773

BDMV-[CO-87]
M88179
M88180 
Table 1 continued

\section{Bean golden mosaic virus}

Bean golden mosaic virus - [Brazil-Campinas 1-1978]

Bean golden mosaic virus - Alagoas [Brazil-Mac2-2010]

Bean golden yellow mosaic virus

Bean golden yellow mosaic virus - [Dominican Republic-1987]

Bean yellow mosaic Mexico virus

Bean yellow mosaic Mexico virus - [Mexico-Mac2-2011]

Bhendi yellow vein Bhubhaneswar virus

Bhendi yellow vein Bhubhaneswar virus - [India-Orissa-2003]

Bhendi yellow vein mosaic virus

Bhendi yellow vein mosaic virus - India [India-Madurai]

Bhendi yellow vein mosaic virus - [India-Maharashtra-NOL751]

Bhendi yellow vein mosaic virus - Haryana [India-Haryana-2007]

Bhendi yellow vein mosaic virus - Pakistan [Pakistan-Faisalabad 201-1995]

Bhendi yellow vein mosaic virus - Tamil Nadu [India-Coimbatore 4-2004]

Bhendi yellow vein mosaic virus - Thanagan [India-Thanagan-2005]

Blainvillea yellow spot virus

Blainvillea yellow spot virus - [Brazil-Coi25-2007]

Blechum interveinal chlorosis virus

Blechum interveinal chlorosis virus - [Mexico-Campeche-2011]

Boerhavia yellow spot virus

Boerhavia yellow spot virus - [Mexico-Yucatan-2005]

Cabbage leaf curl Jamaica virus

Cabbage leaf curl Jamaica virus - [Jamaica-CUc3-2005]

Cabbage leaf curl virus

Cabbage leaf curl virus - [United States-Florida-1996]

Capraria yellow spot Yucatan virus

Capraria yellow spot Yucatan virus - [Mexico-Yucatan-Conkal-2007]

Cassava mosaic Madagascar virus

Cassava mosaic Madagascar virus - [Madagascar-Toliary-2006]

Catharanthus yellow mosaic virus

Catharanthus yellow mosaic virus - [Pakistan-Lahore-KN4]

Centrosema yellow spot virus

Centrosema yellow spot virus - [Brazil-Car1-2009]

Chayote yellow mosaic virus

Chayote yellow mosaic virus - [Nigeria-Ibadan]

Chenopodium leaf curl virus

Chenopodium leaf curl virus - [USA-Florida-Citra-2007]

Cherry tomato leaf curl virus

Cherry tomato leaf curl virus - [India-CTM-2005]

\section{Chilli leaf curl Pakistan virus}

Chilli leaf curl Pakistan virus - Pakistan [Pakistan-Shorkot-2004]

Chilli leaf curl Pakistan virus - China [China-Yunnan 1045-2009]

Chilli leaf curl India virus

Chilli leaf curl India virus - [India-2008]

Chilli leaf curl Kanpur virus

Chilli leaf curl Kanpur virus [India-Kanpur-2008]

\begin{tabular}{|c|c|c|}
\hline BGMV-[BR-Cam1-78] & M88686 & M88687 \\
\hline BGMV-Ala[Brazil-Mac2-2010] & JN419006 & \\
\hline BGYMV-[DO-87] & L01635 & L01636 \\
\hline BYMMxV-[MX-Mac2-11] & FJ944023 & \\
\hline BYVBhV-[IN-Ori-03] & FJ589571 & \\
\hline BYVMV-IN[IN-Mad] & AF241479 & \\
\hline BYVMV-[IN-Mah-NOL751] & EU589392 & \\
\hline BYVMV-Har[IN-Har-07] & FN645923 & \\
\hline BYVMV-[PK-Fai201-95] & AJ002451 & \\
\hline BYVMV-TN[IN-Coi4-04] & FJ179372 & \\
\hline BYVMV-Tha[IN-Tha-05] & FJ176235 & \\
\hline B1YSV-[BR-Coi25-07] & EU710756 & EU710757 \\
\hline BleICV-[MX-Cam-11] & JX827487 & JX827488 \\
\hline BoYSV-[MX-Yuc-05] & EF121755 & \\
\hline CabLCJV-[JM-CUc3-05] & DQ178608 & DQ178609 \\
\hline CabLCV-[US-Flo-96] & U65529 & U65530 \\
\hline CarYSYV-[MX-Yuc-Con-07] & KC426927 & KC426928 \\
\hline CMMGV-[MG-Tol-06] & HE617299 & HE617300 \\
\hline CaYMV-[PK-Lah-KN4] & HE580234 & \\
\hline CeYSV - [BR-Car1-09] & JN419002 & \\
\hline ChaYMV-[NG-Iba] & AJ223191 & \\
\hline ChLCV-[[USA-FL-Cit-07] & HM626515 & \\
\hline CToLCV-[IN-CTM-06] & DQ629102 & \\
\hline ChiLCPKV-PK[PK-Sho-04] & DQ114477 & \\
\hline ChiLCPKV-CN[CN-Yn1045-09] & HM587709 & \\
\hline ChiLCINV-[IN-08] & FM877858 & \\
\hline ChiLCKV-[IN-Kan-08] & HM007106 & \\
\hline
\end{tabular}


Table 1 continued

\section{Chilli leaf curl Vellanad virus}

Chilli leaf curl Vellanad virus - [India-Vellanad-2008]

Chilli leaf curl virus

Chilli leaf curl virus - India [India-Amritsar-Papaya-2009]

Chilli leaf curl virus - [Bangladesh-Gazipur]

Chilli leaf curl virus - Chilli [India-Chilli-2005]

Chilli leaf curl virus - Joydebpur [India-Pondalu-Hibiscus-2007]

Chilli leaf curl virus - Khanewal [Pakistan-Khanewal-2004]

Chilli leaf curl virus - Pakistan [Pakistan-Multan-1998]

Chino del tomate Amazonas virus

Chino del tomate Amazonas virus - [Brazil-AM10-2007]

Chino del tomate virus

Chino del tomate virus - Tomato [Mexico-Sinaloa IC-1983]

Chino del tomate virus - [Mexico-Iguala]

Chino del tomate virus - Soybean [Mexico-Sinaloa-2005]

Cleome golden mosaic virus

Cleome golden mosaic virus - [Brazil-BA 05-2007]

Cleome leaf crumple virus

Cleome leaf crumple virus - [Brazil-BgV05A.1.C75]

Clerodendron yellow mosaic virus

Clerodendron yellow mosaic virus - [India-Iari-2006]

Clerodendrum golden mosaic China virus

Clerodendron golden mosaic China virus - Fuzon [China-Fuzhou 7-2007]

Clerodendron golden mosaic China virus - Jiangsu [China-Jiangsu XY1-2008]

Clerodendrum golden mosaic Jiangsu virus

Clerodendron golden mosaic Jiangsu virus - [China-Jiangsu XY2-2008]

Clerodendrum golden mosaic virus

Clerodendron golden mosaic virus - [Vietnam-Sonla-2005]

Corchorus golden mosaic virus

Corchorus golden mosaic virus - India [India-Bahraich-2008]

Corchorus golden mosaic virus - Hanoi [Vietnam-Hanoi-2005]

Corchorus yellow spot virus

Corchorus yellow spot virus - [Mexico-Yucatan-2005]

Corchorus yellow vein mosaic virus

Corchorus yellow vein mosaic virus - [India-Maharashtra-2011]

Corchorus yellow vein Vietnam virus

Corchorus yellow vein Vietnam virus - [Vietnam-Hoa Binh-2000]

Cotton chlorotic spot virus

Cotton chlorotic spot virus - [Brazil-CampinaGrandeB012-2009]

Cotton leaf crumple virus

Cotton leaf crumple virus - Arizona [Mexico-Sonora-1991]

Cotton leaf crumple virus - Texas [United States-Texas-1991]

Cotton leaf curl Alabad virus

Cotton leaf curl Alabad virus - Alabad [Pakistan-Alabad 804a-1996]

Cotton leaf curl Alabad virus - Haryana [India-Karnal-OY77-Okra-2005]

Cotton leaf curl Alabad virus - Karnal [India-Karnal-OY81B-Okra-2005]

Cotton leaf curl Alabad virus - Lobatum [Pakistan-Multan-Lobatum-2006]
ChiLCVV-[IN-Vel-08]

HM007121

ChiLCV-IN[IN-Amr-Pap-09]

GU136803

ChiLCV-[BD-Gaz]

AJ875159

ChiLCV-Chi[IN-Chi-05]

DQ673859

ChiLCV-JO[IN-Pon-Hib-07]

FJ345402

ChiLCV-Kha[PK-Kha-04]

DQ116878

ChiLCV-PK[PK-Mul-98]

AF336806

CdTAV-[BR-AM10-07]

HM357461

CdTV-To[MX-SinIC-83]

AF101476

AF101478

CdTV-[MX-Igu]

AY751753

CdTV-Sb[MX-Sin-05]

DQ347945

CleGMV-[BR-BA05-07]

HQ396465

CleLCrV-[BR-BgV051C75]

JF694461

JF694465

ClYMV-[IN-Iari-06]

EF408037

ClGMCNV-Fu[CN-Fz7-07]

FJ011668

FJ011669

ClGMCNV-Ji[CN-JsXY1-08]

FN396962

FN396963

ClGMJsV-[CN-JsXY2-08]

FN396966

ClGMV-[VN-Son-05]

DQ641692

DQ641693

CoGMV-Ba[IN-Bah-08]

FJ463902

FJ463901

CoGMV-Ha[VN-Han-05]

DQ641688

DQ641689

CoYSV-[MX-Yuc-05]

DQ875868

DQ875869

CoYV-[IN-Mah-11]

KC196077

CoYVV-[VN-Hoa-00]

AY727903

AY727904

CoChSpV-[BR-Cam-09]

KF358470

CLCrV-AZ[MX-Son-91]

AF480940

AF480941

CLCrV-TX[US-Tex-91]

AY083351

CLCuAlV-Al[PK-Ala804a-96]

AJ002452

CLCuAlV-Ha[IN-Kar-OY77-Okr-05]

GU112081

CLCuAlV-Ka[IN-Kar-OY81B-Okr-05]

GU112004

CLCuAlV-Lo[PK-Mul-Lob-06] 
Table 1 continued

Cotton leaf curl Alabad virus - Multan [Pakistan-Multan-Punctatum-2006]

Cotton leaf curl Bangalore virus

Cotton leaf curl Bangalore virus - [India-Bangalore-2004]

Cotton leaf curl Gezira virus

Cotton leaf curl Gezira virus - Sudan [Sudan-Gezira-1996]

Cotton leaf curl Gezira virus - Burkina Faso [Burkina Faso-Bazega-Okra-2009]

Cotton leaf curl Gezira virus - Cairo [Egypt-Cairo-Hollyhock]

Cotton leaf curl Gezira virus - Cameroon [Cameroon-Muea-Okra-2008]

Cotton leaf curl Gezira virus - Egypt [Egypt-Aswan-Okra]

Cotton leaf curl Gezira virus - Hollyhock [Egypt-Giza-Hollyhock]

Cotton leaf curl Gezira virus - Lysoka [Cameroon-Lysoka11-Okra-2008]

Cotton leaf curl Gezira virus - Madagascar [Madagascar-Fort Dauphin-bean-2001]

Cotton leaf curl Gezira virus - Mali [Mali-Bamako-Okra-2006]

Cotton leaf curl Gezira virus - Niger [Niger-Niamey2-Okra-2007]

Cotton leaf curl Gezira virus - Okra [Sudan-Okra-2007]

\section{Cotton leaf curl Kokhran virus}

Cotton leaf curl Kokhran virus - Kokhran [Pakistan-Faisalabad 1]

Cotton leaf curl Kokhran virus - Burewala [Pakistan-Vehari-2006]

Cotton leaf curl Kokhran virus - Layyah [Pakistan-Layyah-2011]

Cotton leaf curl Kokhran virus - Lucknow [India-Lucknow-Cyamopsis tetragonolobaBean-2010]

Cotton leaf curl Kokhran virus - Shadadpur [Pakistan-Shadadpur-2005]

Cotton leaf curl Multan virus

Cotton leaf curl Multan virus - Darwinii [Pakistan-Multan-Darwinii 1-2006]

Cotton leaf curl Multan virus - Faisalabad [Pakistan-Yazman 62-1995]

Cotton leaf curl Multan virus - Hibiscus [India-Hibiscus1-2011]

Cotton leaf curl Multan virus - Hisar [Pakistan-Multan-H65-1-1997]

Cotton leaf curl Multan virus - Pakistan [Pakistan-Multan-Davidsonii-2006]

Cotton leaf curl Multan virus - Rajasthan [India-Sriganganagar-1994]

Cowpea golden mosaic virus

Cowpea golden mosaic virus - [Nigeria-Nsukka-1990]

Crassocephalum yellow vein virus

Crassocephalum yellow vein virus - [China-Jinhong-2005]

Cucurbit leaf curl virus

Cucurbit leaf curl virus - [United States-Arizona-1991]

Dalechampia chlorotic mosaic virus

Dalechampia chlorotic mosaic virus - [Venezuela-Albarico1020-2007]

Datura leaf distortion virus

Datura leaf distortion virus - [Venezuela-Rubio 933-2007]

Desmodium leaf distortion virus

Desmodium leaf distortion virus - [Mexico-Yucatan-2005]

Dicliptera yellow mottle virus

Dicliptera yellow mottle virus - [United States-Florida-1998]

Dolichos yellow mosaic virus

Dolichos yellow mosaic virus - [Bangladesh-Gazipur]

\begin{tabular}{|c|c|c|}
\hline CLCuAlV-Mu[PK-Mul-Pun-06] & EU384575 & EU384578 \\
\hline CLCuBaV-[IN-Ban-04] & AY705380 & \\
\hline CLCuGeV-SD[SD-Gez-96] & AF260241 & \\
\hline CLCuGeV-BF[BF-Baz-Okr-09] & FN554540 & \\
\hline CLCuGeV-Ca[EG-Cai-Hol] & AJ542539 & \\
\hline $\begin{array}{l}\text { CLCuGeV-CM[CM-Mue-Okr- } \\
08]\end{array}$ & FM210276 & \\
\hline CLCuGeV-EG[EG-Asw-Okr] & AF155064 & \\
\hline CLCuGeV-Ho[EG-Giz-Hol] & AF014881 & \\
\hline $\begin{array}{l}\text { CLCuGeV-Ly[CM-Lys11- } \\
\text { Okr08] }\end{array}$ & FM164726 & \\
\hline $\begin{array}{l}\text { CLCuGeV-MG[MG-FtD-Bea- } \\
01]\end{array}$ & AM701757 & \\
\hline $\begin{array}{l}\text { CLCuGeV-ML[ML-Bam-Okr- } \\
\text { 06] }\end{array}$ & EU024120 & \\
\hline CLCuGeV-NENE-Nia2-Okr-07] & EU432373 & \\
\hline CLCuGeV-Ok[SD-Okr-07] & FJ868828 & \\
\hline CLCuKoV-Ko[PK-Fai1] & AJ496286 & \\
\hline CLCuKoV-Bu[PK-Veh-06] & AM421522 & \\
\hline CLCuKoV-La[PK-Lay-11] & HF549182 & \\
\hline $\begin{array}{l}\text { CLCuKoV-Lu[IN-Luc-Ct- } \\
\text { Bea10] }\end{array}$ & GU385879 & \\
\hline CLCuKoV-Sha[PK-Sha-05] & FN552001 & \\
\hline $\begin{array}{l}\text { CLCuMuV-Dar[PK-Mul-Dar1- } \\
\text { 06] }\end{array}$ & EU365613 & \\
\hline CLCuMuV-Fai[PK-Yaz62-95] & AJ002447 & \\
\hline CLCuMuV-Hib[IN-Hib1-11] & JN807763 & \\
\hline $\begin{array}{l}\text { CLCuMuV-His[PK-Mul-H65-1- } \\
\text { 97] }\end{array}$ & AJ132430 & \\
\hline CLCuMuV-PK[PK-Mul-06] & EU365616 & \\
\hline CLCuMuV-Ra[IN-Sri-94] & AF363011 & \\
\hline CPGMV-[NG-Nsu-90] & AF029217 & \\
\hline CraYVV-[CN-Jin-05] & EF165536 & \\
\hline CuLCuV-[US-Ari-91] & AF256200 & AF327559 \\
\hline DaChMV-[VE-Alb1020-07] & JN848775 & JN848776 \\
\hline DaLDV-[VE-Rub933-07] & JN848773 & JN848774 \\
\hline DesLDV-[MX-Yuc-05] & DQ875870 & DQ875871 \\
\hline DiYMoV-[US-Flo-98] & AF139168 & AF170101 \\
\hline DoYMV-[BD-Gaz] & AY271891 & \\
\hline
\end{tabular}


Table 1 continued

\section{East African cassava mosaic virus}

East African cassava mosaic virus - Kenya [Kenya-Boa-K48-2001]

East African cassava mosaic virus - [Malawi-8N-2007]

East African cassava mosaic virus - Cameroon [Cameroon-1998]

East African cassava mosaic virus - Tanzania [Tanzania-1-2001]

East African cassava mosaic virus - Uganda [Uganda-Mild2-1997]

East African cassava mosaic Kenya virus

East African cassava mosaic Kenya virus - [Kenya-Kathiana-K300-2002]

East African cassava mosaic Malawi virus

East African cassava mosaic Malawi virus - [Malawi-K-1996]

East African cassava mosaic Zanzibar virus

East African cassava mosaic Zanzibar virus - [Kenya-Felunzi-K19-2001]

\section{Emilia yellow vein virus}

Emilia yellow vein virus - [China-Fuzhou 1-2007]

Erectites yellow mosaic virus

Erectites yellow mosaic virus - [Vietnam-Hoabinh-2005]

Eupatorium yellow vein virus

Eupatorium yellow vein virus - A [Japan-Kumamoto]

Eupatorium yellow vein virus - [Japan-SOJ3-2000]

Eupatorium yellow vein virus - B [Japan-MNS2-2000]

Eupatorium yellow vein virus - C [Japan-Yamaguchi]

Eupatorium yellow vein virus - D [Japan-Suya-2007]

Eupatorium yellow vein virus - E [Japan-Kagawa-Tomato-1997]

Euphorbia leaf curl Guangxi virus

Euphorbia leaf curl Guangxi virus - A [China-Guangxi 35-1-2002]

Euphorbia leaf curl virus

Euphorbia leaf curl virus - [China-Fujian-2006]

Euphorbia mosaic virus

Euphorbia mosaic virus - [Cuba-Tobacco-2007]

Euphorbia yellow mosaic virus

Euphorbia yellow mosaic virus - [Brazil-2008]

Euphorbia yellow mosaic virus - Goias [Brazil-GO-Luziania 8675-2009]

French bean leaf curl virus

French bean leaf curl virus - [India-Kanpur-2011]

Hedyotis uncinella yellow mosaic virus

Hedyotis uncinella yellow mosaic virus - [Vietnam-VN1]

Hemidesmus yellow mosaic virus

Hemidesmus yellow mosaic virus - [India-Tirupati-H1-2012]

Hollyhock leaf curl virus

Hollyhock leaf curl virus - [Pakistan-Faisalabad-20-4-06]

Honeysuckle yellow vein virus

Honeysuckle yellow vein virus - Japan [Japan-Sapporo 1-2000]

Honeysuckle yellow vein virus - [Australia-Ayr-BRIP57501-1983]

Honeysuckle yellow vein virus - A [Japan-Fukuoka 1]

Honeysuckle yellow vein virus - B [Japan]

Honeysuckle yellow vein virus - C [Japan-Yamaguchi]

Honeysuckle yellow vein virus - D [Japan-Nara 2-2006]

Honeysuckle yellow vein virus - E [Japan-Nara 1-2006]

Honeysuckle yellow vein virus - Ibaraki [Japan-Ibaraki-Honeysuckle-2006]

Honeysuckle yellow vein virus - Jeju [South Korea-Jeju 138-Tomato-2008]

Honeysuckle yellow vein virus - Kobe [Japan-Hyogo 12-2000]
EACMV-KE[KE-Boa-K48-01]

AJ717542

AJ704949

EACMV-[MW-8N-07]

EACMV-CM[CM-98]

EACMV-TZ[TZ-1-01]

EACMV-UG[UG-Mld2-97]

EACMKV-[KE-Kat-K300-02]

EACMMV-[MW-K-96]

AJ006460

EACMZV-[KE-Fel-K19-01]

AJ717562

AJ704942

EYVV-[CN-Fz1-07]

U377539

ErYMV-[VN-Hoa-05]

DQ641698

EpYVV-A[JR-Kum]

EpYVV-[JR-SOJ3-00]

EpYVV-B[JR-MNS2-00]

EpYVV-C[JR-Yam]

EpYVV-D[JR-Suy-07]

EpYVV-E[JR-Kag-97]

EuLCGxV-A[CN-Gx35-1-02]

AM411424

EuLCuV-[CN-Fuj-06]

FJ487911

EuMV-[CU-Tb-07]

FJ807782

EuMV-[BZ-08]

FJ619507

EuYMV-GO[BR-GO-Luz 8675-09]

JF756676

FbLCV-[IN-Kan-11]

JQ866297

HeuYMV-[VN-VN1]

KF429251

HemYMV-[IN-Tir-H1-12]

KC898543

HoLCV-[PK-Fai-20-4-06]

FR772082

HYVV-JR[JR-SP1-00]

AB 182261

HYVV-[AU-Ayr-BRIP57501-83]

JX416174

HYVV-A[JR-Fuk1]

AB 178945

HYVV-B[JR]

HYVV-C[JR-Yam]

AB020781

AB079765

AB287441

AB287440

HYVV-E[JR-Nar1-06]

AB287439

HYVV-Iba[JR-Iba-06]

HM164545

HYVV-Je[KR-Jeju138-To-08]

AB178946
FJ807783
AF112355

AY795989

AJ704965

83


Table 1 continued

Honeysuckle yellow vein virus - Kochi [Japan-Kochi-Tomato-2000]

Honeysuckle yellow vein virus - Mas [Japan-Masuda-2006]

Honeysuckle yellow vein virus - Nara [Japan-Nara3-2001]

Honeysuckle yellow vein virus - South Korea 1 [South Korea-2007]

Honeysuckle yellow vein virus - South Korea 2 [South Korea-KJ-Tomato-2007]

Honeysuckle yellow vein virus - UK [Japan-Fukui-2006]

Horsegram yellow mosaic virus

Horsegram yellow mosaic virus - [India-Bangalore-2004]

Indian cassava mosaic virus

Indian cassava mosaic virus - India [India-Maharashtra 2-1988]

Indian cassava mosaic virus - [India-Maharashtra-2009]

Indian cassava mosaic virus - Jatropha [India-Dhawad-2008]

Indian cassava mosaic virus - Kerala [India-Kerala 2-2002]

\section{Jacquemontia mosaic Yucatan virus}

Jacquemontia mosaic Yucatan virus - [Mexico-Yucatan-2007]

Jatropha leaf curl virus

Jatropha leaf curl virus - New Delhi [India-New Delhi-2007]

Jatropha leaf curl virus - [India-Gujarat-2009]

\section{Jatropha mosaic India virus}

Jatropha mosaic India virus - [India-Lucknow-2009]

Jatropha mosaic Nigerian virus

Jatropha mosaic Nigerian virus - [Nigeria-2-2011]

Jatropha mosaic virus

Jatropha mosaic virus - [Jamaica-Spanish Town 1-2004]

Jatropha yellow mosaic India virus

Jatropha yellow mosaic India virus - [India-Kathaupahadi-2008]

Kudzu mosaic virus

Kudzu mosaic virus - [China-Fujian-2008]

Lindernia anagallis yellow vein virus

Lindernia anagallis yellow vein virus - [China-Hainan-2004]

Ludwigia yellow vein virus

Ludwigia yellow vein virus - [China-Guangxi 37-2003]

Luffa yellow mosaic virus

Luffa yellow mosaic virus - [Vietnam]

Macroptilium golden mosaic virus

Macroptilium golden mosaic virus - [Jamaica- Augusta Town-2004]

Macroptilium mosaic Puerto Rico virus

Macroptilium mosaic Puerto Rico virus - [Puerto Rico-Bean-1998]

Macroptilium yellow mosaic Florida virus

Macroptilium yellow mosaic Florida virus - [United States-Florida-1985]

Macroptilium yellow mosaic virus

Macroptilium yellow mosaic virus - Cuba [Cuba]

Macroptilium yellow mosaic virus - Jamaica [Jamaica-Mona-2006]

Macroptilium yellow spot virus

Macroptilium yellow spot virus - [Brazil-Agua das Flores 1-2010]

Macroptilium yellow vein virus

Macroptilium yellow vein virus - [Brazil-Maceio 4-2010]

Malvastrum leaf curl Philippines virus

Malvastrum leaf curl Philippines virus - [Philippines-Mc1-2012]
HYVV-Koc[JR-Koc-Tom-00]

HYVV-Mas[JR-Mas-06]

HYVV-Nar[JR-Nar3-01]

HYVV-KR1[KR-07]

HYVV-KR2[KR-KJ-To-07]

HYVV-UK[JR-Fuk-06]

HgYMV-[IN-Ban-04]

ICMV-IN[IN-Mah2-88]

ICMV-[IN-Mah-09]

ICMV-Jat[IN-Dha-08]

ICMV-Ker[IN-Ker2-02]

JacMYuV-[MX-Yuc-07]

JLCuV-ND[IN-ND-07]

JLCuV-Gu[IN-Guj-09]

JMINV-[IN-Luc-09]

JMNV-[NG-2-11]

JMV-[JM-ST1-04]

JYMINV-[IN-Kat-08]

KuMV-[CN-Fuj-08]

LaYVV-[CN-Hn-04]

LuYVV-[CN-Gx37-03]

LYMV-[VN]

MacGMV-[JM-StT-04]

MacMPRV-[PR-Bea-98]

MacYMFV-[US-Flo-85]

MacYMV-CU[CU]

MacYMV-JM[JM-Mon-06]

MaYSV-[BR-Agf1-10]

MaYVV-[BR-Mac4-10]

MaLCPHV-[PH-Mc1-12]

JN419021

KC577540
AB055009

AB236325

AB079689

FJ434943

HM164547

AB236321

AM932427

AM932428

AY730035

AY730036

JF496657

GQ924760

GQ924761

AJ575819

JQ821386

JQ821387

EU798996

GU451249

HM230683

JX025358

KF723258

KF723261

FJ177030

FJ539014

FJ539015

AY795900

AJ965539
AF509739

EU158096

AF449192

AF449193

AY044135

AY044136

AJ344452

EF582840

EF582841

AF509740

EU158097

JN419013 
Table 1 continued

Malvastrum leaf curl virus

Malvastrum leaf curl virus - [China-Guangxi 100 -Papaya-2005]

MaLCuV-[CN-Gx100-Pap-05]

Malvastrum yellow mosaic Helshire virus

Malvastrum yellow mosaic Helshire virus - [Jamaica-2005]

Malvastrum yellow mosaic Jamaica virus

Malvastrum yellow mosaic Jamaica virus - [Jamaica-179A73-2003]

Malvastrum yellow mosaic virus

Malvastrum yellow mosaic virus - [China-Hainan 36-2004]

Malvastrum yellow vein virus

Malvastrum yellow vein virus - [China-Yunnan 206-Ageratum-2003]

Malvastrum yellow vein virus - A [China-Yunnan 278-2004]

Malvastrum yellow vein virus - B [China-Yunnan 340-Sida-2008]

Malvastrum yellow vein Yunnan virus

Malvastrum yellow vein Yunnan virus - [China-Yunnan 160-2003]

Melon chlorotic leaf curl virus

Melon chlorotic leaf curl virus - Costa Rica [Costa Rica-Guanacaste-1998]

Melon chlorotic leaf curl virus - [Costa Rica-Cucurbita-2A-2003]

Melon chlorotic leaf curl virus - Guatemala [Guatemala-2000]

Melon chlorotic mosaic virus

Melon chlorotic mosaic virus - [Venezuela-Watermelon-2009]

Merremia leaf curl virus

Merremia leaf curl virus - [Puerto Rico-N1-2006]

\section{Merremia mosaic virus}

Merremia mosaic virus - Venezuela [Venezuela-Trujillo]

Merremia mosaic virus - Puerto Rico [Puerto Rico-]

\section{Merremia mosaic Puerto Rico virus}

Merremia mosaic Puerto Rico virus - [Puerto Rico-89-1998]

Mesta yellow vein mosaic Bahraich virus

Mesta yellow vein mosaic Bahraich virus - [India-Bahraich-2007]

Mesta yellow vein mosaic virus

Mesta yellow vein mosaic virus - Andhra Pradesh [India-Amadalavalasa 27-2008]

Mesta yellow vein mosaic virus - [Pakistan-Changa Manga-2009]

Mesta yellow vein mosaic virus - Bengal [India-Bongaon-Leaf curl-2007]

Mimosa yellow leaf curl virus

Mimosa yellow leaf curl virus - [Vietnam-Binhduong-2005]

\section{Mungbean yellow mosaic India virus}

Mungbean yellow mosaic India virus - [India- Sriganganagar-Mungbean 1-1996]

Mungbean yellow mosaic virus

Mungbean yellow mosaic virus - [India-Madurai-Soybean]

Okra enation leaf curl virus

Okra enation leaf curl virus - [India-Sonipat EL10-2006]

Okra mottle virus

Okra mottle virus - [Brazil-6319-2008]

Okra yellow crinkle virus

Okra yellow crinkle virus - Cameroon [Cameroon-Muea-2008]

Okra yellow crinkle virus - [Cameroon-Njombe 5-2007]

Okra yellow crinkle virus - Mali [Mali-Bamako 4-2006]

Okra yellow mosaic Mexico virus

Okra yellow mosaic Mexico virus - [Mexico-Mazatepec 3-2004]

Papaya leaf crumple virus

Papaya leaf crumple virus - [India-Nirulas-2007]

\begin{tabular}{|c|c|c|}
\hline MaYMHeV-[JM-05] & FJ600483 & \\
\hline MaYMJV-[JM-179A73-03] & FJ601917 & FJ600485 \\
\hline MaYMV-[CN-Hn36-04] & AM236755 & \\
\hline MaYVV-[CN-Yn206-Age-03] & AJ744881 & \\
\hline MaYVV-A[CN-Yn278-04] & FN386459 & \\
\hline MaYVV-C[CN-Yn340-Sid-08] & FN806779 & \\
\hline MaYVYnV-[CN-Yn160-03] & AJ786711 & \\
\hline MCLCuV-CR[CR-Gua-98] & AY064391 & AF440790 \\
\hline MCLCuV-[CR-Cuc-2A-03] & KC153490 & \\
\hline MCLCuV-GT[GT-00] & AF325497 & AF325498 \\
\hline MCIMV-[VN-Wat-09] & HM163576 & HM163577 \\
\hline MerLCV-[PR-N1-06] & DQ644561 & \\
\hline MerMV-VE[VE-Tru] & AY508991 & AY508992 \\
\hline MerMV-PR[PR] & AF068636 & AY965899 \\
\hline MerMPRV-[PR-PR89-98] & FJ944021 & FJ944022 \\
\hline MeYVMBaV-[IN-Bah-07] & EU360303 & \\
\hline MeYVMV-And[IN-Ama27-08] & FJ159269 & \\
\hline MeYVMV-[PK-CM-09] & FR715681 & \\
\hline MeYVMV-Ben[IN-Bon-LC-07] & FJ345400 & \\
\hline MiYLCV-[VN-Bin-05] & DQ641695 & \\
\hline MYMIV-[IN-Sri-Mg1-96] & AF416742 & AF416741 \\
\hline MYMV-[IN-Mad-Sb] & AJ421642 & AJ867554 \\
\hline OELCuV-[IN-SonEL10-06] & GU111996 & \\
\hline OMoV-[BR-6319-08] & EU914817 & EU914818 \\
\hline OYCrV-CM[CM-Mue-08] & FM210275 & \\
\hline OYCrV-[CM-Njo5-07] & HE793424 & \\
\hline OYCrV-ML[ML-Bam4-06] & EU024119 & \\
\hline OYMV-[MX-Maz3-04] & DQ022611 & GU972604 \\
\hline PaLCrV-[IN-Nir-07] & HM140368 & \\
\hline
\end{tabular}


Table 1 continued

\section{Papaya leaf curl China virus}

Papaya leaf curl China virus - Ageratum [China-Guangxi 10-Ageratum2002]

Papaya leaf curl China virus - [China-Hainan-HK7-2008]

Papaya leaf curl China virus - Guangxi [China-Guangxi 4-Tomato-2008]

Papaya leaf curl China virus - Papaya [China-Guangxi 30-Tomato-2002]

Papaya leaf curl China virus - Tomato [China-Guangxi 12-Tomato-2002]

Papaya leaf curl China virus - Vietnam [Vietnam-Hanoi 112-2007]

Papaya leaf curl Guangdong virus

Papaya leaf curl Guangdong virus - [China-Fujian-Euphorbia-2006]

Papaya leaf curl virus

Papaya leaf curl virus - Lucknow [India-Lucknow]

Papaya leaf curl virus - A [India-WB-Cr-Croton-2008]

Papaya leaf curl virus - Amaranthus [India-Lucknow-Amaranthus-2011]

Papaya leaf curl virus - Aster [India-Lucknow-Aster-2011]

Papaya leaf curl virus - Cirica [India-PaND13-2012]

Papaya leaf curl virus - Croton[India-Croton]

Papaya leaf curl virus - India [India-Pataudi-Radish-2009]

Papaya leaf curl virus - Lahore [Pakistan-Lahore-HYDNA-Alcea rosea2006]

Papaya leaf curl virus - Pakistan [Pakistan-Cotton-2002]

Papaya leaf curl virus - Punjab [Pakistan-Punjab-Cro-2006]

Papaya leaf curl virus - Rhynchosia [Pakistan-Mianwali-Rhynchosia capitata-2007]

Papaya leaf curl virus - Sikar [India-Sikar-Calotropis procera-2010]

Papaya leaf curl virus - Soybean [India-Lucknow-Soybean-2011]

Papaya leaf curl virus - Tobacco[India-Lucknow-Nicotiana glutinosa-2010]

Papaya leaf curl virus - Tomato [India-CTM-Tomato-2005]

Passionfruit severe leaf distortion virus

Passionfruit severe leaf distortion virus - [Brazil-LSN 2-2001]

Pedilanthus leaf curl virus

Pedilanthus leaf curl virus - [Pakistan-Multan-2006]

Pedilanthus leaf curl virus - Euphorbia [Pakistan-Rahim Yar Khan 1-Tomato-2004]

Pedilanthus leaf curl virus - Soybean [Pakistan-Nawab Shah-Soybean-2009]

Pepper golden mosaic virus

Pepper golden mosaic virus - United States [United States-Mosaic-1987]

Pepper golden mosaic virus - Costa Rica [Costa Rica]

Pepper golden mosaic virus - [Costa Rica-Llano Grande-2008]

Pepper huasteco yellow vein virus

Pepper huasteco yellow vein virus - [Mexico-Tamaulipas]

Pepper leaf curl Bangladesh virus

Pepper leaf curl Bangladesh virus - Bangladesh [Bangladesh-Bogra-1999]

Pepper leaf curl Bangladesh virus - [Pakistan-Lahore-2004]

Pepper leaf curl Bangladesh virus - India [India-Coimbatore-2008]

Pepper leaf curl Bangladesh virus - Pakistan [Pakistan-Khanewal-2004]

Pepper leaf curl Lahore virus

Pepper leaf curl Lahore virus - [India-Lucknow-2011]

Pepper leaf curl virus

Pepper leaf curl virus - Malaysia [Malaysia-Klang-1997]

Pepper leaf curl virus - Thailand [Thailand]
PaLCuCNV-Age[CN-Gx10-02] AJ558125

PaLCuCNV-[CN-Hn-HK7-08] FN256261

PaLCuCNV-Gx[CN-Gx8-To-08] FN297834

PaLCuCNV-Pap[CN-Gx30-Tom-02] AJ558117

PaLCuCNV-To[CN-Gx12-02] AJ558116

PaLCuCNV-VN[VN-Han112-07] GQ373254

PaLCuGdV-[CN-Fuj-Eu-06] $\quad$ FJ495184

PaLCuV-Luc[IN-Luc] Y15934

PaLCuV-A[IN-WB-Cr-Cro-08] JN817517

PaLCuV-Ama[PK-Luc-Am-11] JN135233

PaLCuV-Ast[PK-Luc-As-11] JQ954859

PaLCuV-Cir[IN-PaND13-12] KF307208

PaLCuV-Cro[IN-Cro] AJ507777

PaLCuV-IN[IN-Pat-Rad-09] FJ593629

PaLCuV-Lah[PK-Lah-HYDNA-Alc-06] FN678906

PaLCuV-PK[PK-Cot-02]

AJ436992

PaLCuV-Pun[PK-Pun-Cro-06]

FN543112

PaLCuV-Rh[PK-Mia-Rc-07]

FM955601

PaLCuV-Sik[In-Sik-Cal-10]

JQ407224

PaLCuV-Soy[IN-Luc-Soy-11]

JN807765

PaLCuV-Tob[IN-Luc-Nic-10]

HM143914

PaLCuV-Tom[IN-CTM-Tom-06]

DQ629102

PSLDV-[BR-LSN2-01]

FJ972767

FJ972768

PeLCV-[PK-Mul-06]

AM712436

PeLCV-Eu[PK-RYK1-To-04]

DQ116884

PeLCV-Sb[PK-NS-Sb-09]

AM948961

PepGMV-US[US-Mos-87]

AY928512

AY928513

PepGMV-CR[CR]

AF149227

PepGMV-[CR-LG-08]

JQ743486

PHYVV-[MX-Tam]

X70418

X70419

AF314531

PepLCBV-BD[BD-Bog-99]

AM404179

HM007096

DQ116881

PepLCBV-PK[PK-Kha-04]

JN135234

PepLCLaV-[IN-Luc-11]

AF414287

PepLCV-MY[MY-Kla-97]

AF134484 
Table 1 continued

Pepper leaf curl Yunnan virus

Pepper leaf curl Yunnan virus - [China-Yunnan323-2007]

Pepper yellow leaf curl China virus

Pepper yellow leaf curl China virus - [China-YN65-1-2010]

Pepper yellow leaf curl Indonesia virus

Pepper yellow leaf curl Indonesia virus - [Indonesia-2005]

Pepper yellow vein Mali virus

Pepper yellow vein Mali virus - [Burkina Faso-Banfora-hot pepper1-2009]

Potato yellow mosaic virus

Potato yellow mosaic virus - Potato [Venezuela-1991]

Potato yellow mosaic virus - [Trinidad and Tobago-Tomato-1996]

Potato yellow mosaic virus - Colombia [Colombia-Valle del Cauca-Tomato-2007]

Potato yellow mosaic virus - Tomato [Puerto Rico-Tomato-2004]

Pouzolzia golden mosaic virus

Pouzolzia golden mosaic virus - [China-TY01-2012]

Pouzolzia mosaic Guangdong virus

Pouzolzia mosaic Guangdong virus - [Taiwan-Miaoli-ML13W1-2013]

Premna leaf curl virus

Premna leaf curl virus - [Vietnam-VN7-2011]

Pumpkin yellow mosaic Malaysia virus

Pumpkin yellow mosaic Malaysia virus - [Malaysia-Negeri Sambilan-2001]

Radish leaf curl virus

Radish leaf curl virus - [India-Varanasi-2005]

Radish leaf curl virus - Tomato [Pakistan-Bihar-Tomato-2009]

Rhynchosia golden mosaic Havana virus

Rhynchosia golden mosaic Havana virus - [Cuba-Havana-2007]

Rhynchosia golden mosaic virus

Rhynchosia golden mosaic virus - Mexico [Mexico-Sinaloa-2005]

Rhynchosia golden mosaic virus - Honduras [Mexico-Chiapas-Tobacco]

Rhynchosia golden mosaic virus - Soybean [Mexico-Sinaloa 4-Soybean-2007]

Rhynchosia mild mosaic virus

Rhynchosia mild mosaic virus - [Puerto Rico-PR79-1997]

Rhynchosia rugose golden mosaic virus

Rhynchosia rugose golden mosaic virus - [Cuba-Camaguey-2009]

Rhynchosia yellow mosaic India virus

Rhynchosia yellow mosaic India virus - [India-Thiruvananthapuram-JRH1-2009]

Rhynchosia yellow mosaic virus

Rhynchosia yellow mosaic virus - [Pakistan-Lahore33-2007]

Rose leaf curl virus

Rose leaf curl virus - [Pakistan-Faisalabad-2006]

Sauropus leaf curl virus

Sauropus leaf curl virus - [Thailand-Kamphaengsaen-AFSP5e-2010]

Senecio yellow mosaic virus

Senecio yellow mosaic virus - [China-Guangxi 46-2003]

Sida ciliaris golden mosaic virus

Sida ciliaris golden mosaic virus - [Venezuela-Lara-M3-2009]

Sida common mosaic virus

Sida common mosaic virus - [Brazil-Coimbra 4-2007]

Sida golden mosaic Braco virus

Sida golden mosaic Braco virus - [Jamaica-Liguanea-A4-2008]

\begin{tabular}{|c|c|c|}
\hline PepLCYnV-[CN-Yn323-07] & EU585781 & \\
\hline PepYLCCNV-[CN-YN65-1-10] & KC149938 & \\
\hline PepYLCIV-[ID-05] & AB267834 & AB267835 \\
\hline PepYVMLV-[BF-Ban-Hpe1-09] & FN555172 & \\
\hline PYMV-Po[VE-91] & D00940 & D00941 \\
\hline PYMV-[TT-Tom-96] & AF039031 & AF039032 \\
\hline PYMV-Co[CO-VdC-Tom-07] & EU518935 & \\
\hline PYMV-To[PR-Tom-04] & AY965897 & AY965898 \\
\hline PouGMV-[CN-TY01-12] & JX183732 & \\
\hline PouMGDV-[TW-Mia-ML13W1-13] & KF414123 & \\
\hline PreLCV-[VN-VN7-11] & JQ793786 & \\
\hline PuYMV-[MY-Neg-01] & EF197941 & \\
\hline RaLCuV-[IN-Var-03] & EF175733 & \\
\hline RaLCuV-To[PK-Bih-To-09] & GU732204 & \\
\hline RhGMHaV-[CU-Hav-07] & HM236368 & HM236369 \\
\hline RhGMV-MX[MX-Sin-05] & DQ347950 & DQ356429 \\
\hline RhGMV-HN[MX-Chi-Tob] & AF408199 & \\
\hline RhGMV-Sb[MX-Sin4-Sb-07] & EU339936 & EU339937 \\
\hline RhMMV-[PR-PR79-97] & FJ944019 & \\
\hline RhRGMV-[CU-Cam-09] & HM236370 & HM236371 \\
\hline RhYMIV-[IN-Thi-JRH1-09] & HM777508 & HM777510 \\
\hline RhYMV-[PK-Lah33-07] & AM999981 & AM999982 \\
\hline RoLCuV-[PK-Fai-06] & GQ478342 & \\
\hline SauLCuV-[TH-Kam-AFSP5e-10] & JN809820 & \\
\hline SeYMV-[CN-Gx46-03] & AJ876550 & \\
\hline SicGMV-[VE-Lar-M3-09] & JX857691 & \\
\hline SiCMV-[BR-Coi4-07] & EU710751 & \\
\hline SiGMBcV-[JM-Lin-A4-08] & JX162595 & \\
\hline
\end{tabular}


Table 1 continued

Sida golden mosaic Brazil virus

Sida golden mosaic Brazil virus - [Brazil-Mato Grosso do Sul-2007]

Sida golden mosaic Buckup virus

Sida golden mosaic Buckup virus - [Jamaica-St Elizabeth 1-2004]

Sida golden mosaic Costa Rica virus

Sida golden mosaic Costa Rica virus - [Costa Rica]

Sida golden mosaic Florida virus

Sida golden mosaic Florida virus - Malvastrum [Cuba-Havana-Malvastrum-1112009]

Sida golden mosaic Florida virus - [United States-Homestead-A1]

Sida golden mosaic Lara virus

Sida golden mosaic Lara virus - [Venezuela-Lara-M1-2009]

Sida golden mosaic virus

Sida golden mosaic virus - [United States-Florida]

Sida golden mottle virus

Sida golden mottle virus - [United States-Florida-Bradenton-1997]

Sida golden yellow vein virus

Sida golden yellow vein virus - [Cuba-Havana]

Sida leaf curl virus

Sida leaf curl virus - [China-Hainan 57-2004]

Sida micrantha mosaic virus

Sida micrantha mosaic virus - [Brazil-A2B2]

Sida micrantha mosaic virus - Rhombifolia [Bolivia-Cerro Fraile 2-2007]

Sida micrantha mosaic virus - Santaremensi [BR-GO-Luziania 780-2003]

Sida mosaic Bolivia virus 1

Sida mosaic Bolivia virus 1 - [Bolivia-Sida micrantha-2007]

Sida mosaic Bolivia virus 2

Sida mosaic Bolivia virus 2 - [Bolivia-Sida micrantha-2007]

Sida mosaic Sinaloa virus

Sida mosaic Sinaloa virus - [Mexico-Guasave-2006]

Sida mottle Alagoas virus

Sida mottle Alagoas virus - [BR-Alagoas-Vicosa 2-2010]

Sida mottle virus

Sida mottle virus - Micrantha [Brazil-A1B3]

Sida mottle virus - Rhombifolia [Brazil-Vicosa 1-1999]

Sida yellow blotch virus

Sida yellow blotch virus - [Brazil-Rio Largo 1-2010]

Sida yellow leaf curl virus

Sida yellow leaf curl virus - [Brazil-Coimbra3-2007]

Sida yellow mosaic Alagoas virus

Sida yellow mosaic Alagoas virus - [Brazil-Alagoas-Vicosa 3-2010]

Sida yellow mosaic China virus

Sida yellow mosaic China virus - [China-Hainan 7-Ageratum-2003]

Sida yellow mosaic virus

Sida yellow mosaic virus - [Brazil-Vicosa 2-1999]

Sida yellow mosaic Yucatan virus

Sida yellow mosaic Yucatan virus - [Mexico-Yucatan-2005]

Sida yellow mottle virus

Sida yellow mottle virus - [Cuba-Sancti Spiritus159-1-2009]

Sida yellow vein Vietnam virus

Sida yellow vein Vietnam virus - [Vietnam-Hanoi-2005]

\begin{tabular}{|c|c|c|}
\hline SiGMBRV-[BR-MS-07] & FN436001 & \\
\hline SiGMBuV-[JM-SE1-04] & HQ008338 & HQ009518 \\
\hline SiGMCRV-[CR] & X99550 & X99551 \\
\hline $\begin{array}{l}\text { SiGMFIV-Malv[CU-Hav-Mal-111- } \\
\text { 09] }\end{array}$ & НМ003779 & HМ003778 \\
\hline SiGMFlV-[US-Hom-A1] & U77963 & \\
\hline SiGMLaV-[VE-Lar-M1-09] & JX857693 & \\
\hline SiGMV-[US-Flo] & AF049336 & AF039841 \\
\hline SiGMoV-[US-Flo-Bra-97] & GU997691 & GU997692 \\
\hline SiGYVV-[CU-Hav] & AJ577395 & \\
\hline SiLCuV-[CN-Hn57-04] & AM050730 & \\
\hline SiMMV-[BR-A2B2] & AJ557451 & AJ557453 \\
\hline SiMMV-Rho[Bo-CF2-07] & HM585439 & \\
\hline SiMMV-San[BR-GO-Luz780-03] & JX415187 & \\
\hline SiMBoV1-[BO-mic-07] & HM585441 & \\
\hline SiMBoV2-[BO-mic-07] & HM585443 & \\
\hline SiMSiV-[MX-Gua-06] & DQ520944 & DQ356428 \\
\hline SiMoAV-[BR-AL-Vsa2-10] & JX871385 & \\
\hline SiMoV-Mic[BR-A1B3] & AJ557450 & AJ557454 \\
\hline SiMoV-Rho[BR-Vic1-99] & AY090555 & \\
\hline SiYBV-[BR-Rla1-10] & JX871380 & \\
\hline SiYLCV-[BR-Coi3-07] & EU710750 & \\
\hline SiYMAV-[BR-AL-Vsa3-10] & JX871383 & \\
\hline SiYMCNV-[CN-Hn7-Age-03] & AM048837 & \\
\hline SiYMV-[BR-Vic2-99] & AY090558 & \\
\hline SiYMYuV-[MX-Yuc-05] & DQ875872 & DQ875873 \\
\hline SiYMoV-[CU-SSp159-1-09] & JN411687 & JN411688 \\
\hline SiYVVV-[VN-Han-05] & DQ641696 & \\
\hline
\end{tabular}


Table 1 continued

Sida yellow vein virus

Sida yellow vein virus - [Honduras-yellow vein]

Sidastrum golden leaf spot virus

Sidastrum golden leaf spot virus - [Brazil-DF334-2010]

Siegesbeckia yellow vein Guangxi virus

Siegesbeckia yellow vein Guangxi virus - [China-Guangxi 111-2005]

Siegesbeckia yellow vein virus

Siegesbeckia yellow vein virus - [China-Guangdong 13-2004]

Solanum mosaic Bolivia virus

Solanum mosaic Bolivia virus - [Bolivia-2007]

South African cassava mosaic virus

South African cassava mosaic virus - [Madagascar-12]

Soybean blistering mosaic virus

Soybean blistering mosaic virus - [Argentina-NOA-2005]

Soybean chlorotic blotch virus

Soybean chlorotic blotch virus - [Nigeria-Soybean 19-2007]

Soybean mild mottle virus

Soybean mild mottle virus - [Nigeria-Soybean 17-2007]

Spilanthes yellow vein virus

Spilanthes yellow vein virus - [Vietnam-Dalat-2005]

Spinach yellow vein Sikar virus

Spinach yellow vein Sikar virus - [India-Sikar-AS22]

Squash leaf curl China virus

Squash leaf curl China virus - China [China-Guangxi25-2005]

Squash leaf curl China virus - [Philippines-Benguet-P54]

Squash leaf curl China virus - India [Pakistan-Lahore-2004]

Squash leaf curl China virus - Thailand [Thailand-Nakhon Pathom-Wax Gourd-2007]

Squash leaf curl Philippines virus

Squash leaf curl Philippines virus - [Philippines-Batangas P133-Pumpkin-2007]

Squash leaf curl virus

Squash leaf curl virus - [Jordan-Malva-2006]

Squash leaf curl Yunnan virus

Squash leaf curl Yunnan virus- [China-Yunnan-Y23]

Squash mild leaf curl virus

Squash mild leaf curl virus - [United States-Imperial Valley-1979]

Sri Lankan cassava mosaic virus

Sri Lankan cassava mosaic virus - India [India-Adivaram-2003]

Sri Lankan cassava mosaic virus - Sri Lanka [Sri Lanka-Colombo-1998]

Stachytarpheta leaf curl virus

Stachytarpheta leaf curl virus - [China-Hainan 30-2004]

Sunn hemp leaf distortion virus

Sunn hemp leaf distortion virus - [India-Barrackpore 1-2008]

Sweet potato leaf curl Canary virus

Sweet potato leaf curl Canary virus - [Spain-Canary Islands-BG4-2002]

Sweet potato leaf curl China virus

Sweet potato leaf curl China virus - [China-2005]

SiYVV-[HN-yv]

Y11099

Y11100

SidGLSV-[BR-DF334-10]

SgYVGxV-[CN-Gx111-05]

SgYVV-[CN-Gd13-04]

SoMBoV-[BO-07]

SACMV-[MG-12]

SbBMV-[AR-NOA-05]

SbCBV-[NG-Sb19-07]

SbMMoV-[NG-Sb17-07]

SpYVV-[VN-Dal-05]

SpiYVSKV-[IN-Sik-AS22]

SLCCNV-CN[CN-Gx25-05]

SLCCNV-[PH-Ben-P54]

SLCCNV-IN[PK-Lah-04]

SLCCNV-TH[TH-NP-WG-07]

SLCuPV-[PH-BatP133-Pum-07]

SLCuV-[JD-Mal-06]

SLCuYV-[CN-Yun-Y23]

SMLCuV-[US-IV-79]

SLCMV-IN[IN-Adi-03]

SLCMV-LK[LK-Col-98]

StaLCuV-[CN-Hn30-04]

SHLDV-[IN-Bar-08]

SPLCCV-[ES-CI-BG4-02]

SPLCCNV-[CN-05]

SPLCGV-[US-Geo-16]

AJ810156

Sweet potato leaf curl Georgia virus

Sweet potato leaf curl Georgia virus - [United States-Georgia-16]

Sweet potato leaf curl Henan virus

Sweet potato leaf curl Henan virus - [China-Henan 10-2012]
EF532620

AJ420319

AF421552

AJ579307

AJ314737

AM286794

EU543562

EF532621

AF421553

AJ579308

AJ314738
EF456742

DQ512731

AF326775

SPLCHnV-[CN-Hn10-12] 
Table 1 continued

Sweet potato leaf curl Sao Paulo virus

Sweet potato leaf curl Sao Paulo virus - [Brazil-Sao Paulo-Alvares Machado-2009]

SPLCSPV-[BR-SP-AlvM-09]

HQ393477

Sweet potato leaf curl Sichuan virus 1

Sweet potato leaf curl Sichuan virus 1 - [China-Sichuan 15-2012]

Sweet potato leaf curl Sichuan virus 2

Sweet potato leaf curl Sichuan virus 2 - [China-Sichuan 14-2012]

Sweet potato leaf curl South Carolina virus

Sweet potato leaf curl South Carolina virus - [United States-South Carolina-648-B9-2006]

Sweet potato leaf curl Uganda virus

Sweet potato leaf curl Uganda virus - [Uganda-Kampala-2008]

Sweet potato leaf curl virus

Sweet potato leaf curl virus - China [China-Yunnan-RL31-2006]

Sweet potato leaf curl virus - [Spain-1998]

Sweet potato leaf curl virus - Brazil [Brazil-Para-Belem1-2008]

Sweet potato leaf curl virus - Fujian [China-Jujian-Fp3-2007]

Sweet potato leaf curl virus - Italy [Italy-Sicily-2002]

Sweet potato leaf curl virus - Japan [Japan-Miyazaki-1996]

Sweet potato leaf curl virus - Paraiba [Brazil-Paraiba-Souza1-2008]

Sweet potato leaf curl virus - Pernambuco [Brazil-Rondonia-Porto Velho-2008]

Sweet potato leaf curl virus - Puerto Rico [Puerto Rico-80-N2-2006]

Sweet potato leaf curl virus - Rondonia [Brazil-Bahia-Utinga-2008]

Sweet potato leaf curl virus - Sao Paulo [Brazil-Sao Paulo-Alvares Machado-2009]

Sweet potato leaf curl virus - South Carolina [United States-South Carolina-646-B11-2006]

Sweet potato leaf curl virus - Spain [Spain-Canary Islands-BG6-2002]

Sweet potato leaf curl virus - United States [United States- Louisiana-1994]

Sweet potato mosaic virus

Sweet potato mosaic virus - [Brazil-Brasilia1-2008]

Tobacco curly shoot virus

Tobacco curly shoot virus - [China-Alternanthera-2008]

Tobacco leaf curl Comoros virus

Tobacco leaf curl Comoros virus - [Comoros-Simboussa-2004]

Tobacco leaf curl Cuba virus

Tobacco leaf curl Cuba virus - [Cuba-Taguasco-2005]

Tobacco leaf curl Pusa virus

Tobacco leaf curl Pusa virus - [India-Pusa-2009]

Tobacco leaf curl Thailand virus

Tobacco leaf curl Thailand virus - [Thailand-Tomato-2005]

Tobacco leaf curl Yunnan virus

Tobacco leaf curl Yunnan virus - China [China-Yunnan 136-2002]

Tobacco leaf curl Zimbabwe virus

Tobacco leaf curl Zimbabwe virus - [Comoros-Foumboudziouni-2005]

Tobacco leaf rugose virus

Tobacco leaf rugose virus - [Cuba-Havana-2001]

Tobacco mottle leaf curl virus

Tobacco mottle leaf curl virus - [Cuba-Sanci Spiritus-2003]

Tobacco yellow crinkle virus

Tobacco yellow crinckle virus - [Cuba-2007]

Tomato bright yellow mosaic virus

Tomato bright yellow mosaic virus - [Brazil-BA167-2012]
SPLCSiV-1-[CN-Sc15-12] KC488316

SPLCSiV-2-[CN-Sc14-12] KF156759

SPLCSCV-[US-SC-648-B9-06] HQ333144

SPLCUV-[UG-KAMP-08] TR751068

SPLCV-CN[CN-Yn-RL31-06] EU253456

SPLCV-[ES-98] AJ132548

SPLCV-BR[BR-PA-Bel1-08] FJ969829

SPLCV-Fu[CN-Fuj-Ip3-07] FJ515898

SPLCV-IT[IT-Sic-02] AJ586885

SPLCV-JP[JR-Miy-96] AB433786

SPLCV-PB[BR-PB-Sou1-08] FJ969830

SPLCV-PE[BR-RO-PV-08] HQ393456

SPLCV-PR[PR-80-N2-06] DQ644562

SPLCV-RO[BR-BA-Uti-08] HQ393447

SPLCV-SP[BR-SP-AlvM-09] HQ393473

SPLCV-SC[US-SC-646-B11- HQ333138

06]

SPLCV-ES[ES-CI-BG6-02] EF456744

SPLCV-US[US-Lou-94] AF104036

SPMV-[BR-BSB1-08] FJ969831

TbCSV-[CN-Alt-08] GU199583

TbLCKMV-[KM-Sim-04] AM701760

TbLCuCV-[CU-Tag-05] AM050143

TbLCPuV-To[IN-Pus-09] HQ180391

TbLCTHV-[TH-To-05] I D871221

TbLCYnV-CN[CN-Yn136-02] AJ512761

TbLCZV-[KM-Fou-05] AM701756

TbLRV-[CU-Hav-01] AJ488768

TbMoLCV-[CU-SS-03] I F160943

TbYCV-[CU-07] FJ213931

HQ896204

ToBYMV-[BR-BA167-12] $\quad$ KC791690 
Table 1 continued

Tomato bright yellow mottle virus

Tomato bright yellow mottle virus - [Brazil-TO167-2008]

Tomato chino La Paz virus

Tomato chino La Paz virus - A [Mexico-Baja La Paz-2002]

Tomato Chino La Paz virus - [Mexico-SLP4-2011]

Tomato chino La Paz virus - B [Mexico-Baja El Carrizal-2002]

Tomato chlorotic leaf distortion virus

Tomato chlorotic leaf distortion virus - [Venezuela-Zulia-2004]

Tomato chlorotic mottle virus

Tomato chlorotic mottle virus - Bahia [Brazil-Seabra 1-1996]

Tomato chlorotic mottle virus - [Brazil-Florestal 211-2008]

Tomato chlorotic mottle virus - Minas Gerais [Brazil-Betim 1-1996]

Tomato common mosaic virus

Tomato common mosaic virus - [Brazil-Coimbra 22-2007]

Tomato curly stunt virus

Tomato curly stunt virus - [South Africa-Onderberg-1998]

Tomato dwarf leaf virus

Tomato dwarf leaf virus - [Argentin-Pichanal 397-2008]

Tomato golden leaf distortion virus

Tomato golden leaf distortion virus - [Brazil-TO45-2007]

Tomato golden leaf spot virus

Tomato golden leaf spot virus - [Brazil-Araguaina-TO83-2013]

Tomato golden mottle virus

Tomato golden mottle virus - [Mexico-San Luiz Potosi-2005]

Tomato golden mosaic virus

Tomato golden mosaic virus - [Brazil-Common-1984]

Tomato golden vein virus

Tomato golden vein virus - [Brazil-Ita1220-2003]

Tomato interveinal chlorosis virus

Tomato interveinal chlorosis virus - [Brazil-Pernambuco-Mdc2681-2004]

Tomato leaf curl Anjouan virus

Tomato leaf curl Anjouan virus - [Comoros-Ouani-2004]

Tomato leaf curl Arusha virus

Tomato leaf curl Arusha virus - [Tanzania-Kilimandjaro-2005]

Tomato leaf curl Bangalore virus

Tomato leaf curl Bangalore virus - A [India-Bangalore 1]

Tomato leaf curl Bangalore virus - [India-Hessaraghatta-TC265-2010]

Tomato leaf curl Bangalore virus - B [India-Bangalore 5]

Tomato leaf curl Bangalore virus - C [India-Bangalore 4-1997]

Tomato leaf curl Bangalore virus - D [India-Kerala II-2005]

Tomato leaf curl Bangladesh virus

Tomato leaf curl Bangladesh virus - [Bangladesh-BD2]

Tomato leaf curl Cebu virus

Tomato leaf curl Cebu virus - [Philippines-Nueva Ecita P2-1-2007]

Tomato leaf curl China virus

Tomato leaf curl China virus - Baise [China-Guangxi 32-2002]

Tomato leaf curl China virus - [China-Guangxi-Tobacco-JX-2-2010]

Tomato leaf curl China virus - Nanning1 [China-Guangxi 18-2002]

Tomato leaf curl China virus - Nanning2 [China-Guangxi 63-2003]

Tomato leaf curl Diana virus

Tomato leaf curl Diana virus - [Madagascar-Namakely-2001]

\begin{tabular}{|c|c|c|}
\hline ToBYMoV-[BR-TO167-08] & КC791691 & \\
\hline ToChLPV-A[MX-BLP-02 & AY339618 & \\
\hline ToChLPV-[MX-SLP4-11] & JN676150 & \\
\hline ToChLPV-A[MX-BEC-02] & AY339619 & \\
\hline ToCILDV-[VE-Zul-04] & HQ201952 & \\
\hline ToCMoV-BA[BR-Sea1-96] & AF490004 & AF491306 \\
\hline ToCMoV-[BR-Flo211-08] & KC706561 & \\
\hline ToCMoV-MG[BR-Bet1-96] & AY090557 & \\
\hline ToCmMV-[BR-Coi22-07] & EU710754 & EU710755 \\
\hline ToCSV-[ZA-Ond-98] & AF261885 & \\
\hline ToDfLV-[AR-Pic397-08] & JN564749 & \\
\hline ToGLDV-[BR-TO45-07] & HM357456 & \\
\hline ToGLSV-[BR-Ara-TO83-13] & KC626021 & \\
\hline ToGMoV-[MX-SLP-05] & DQ520943 & DQ406674 \\
\hline TGMV-[BR-Com-84] & K02029 & K02030 \\
\hline TGVV-[BR-Ita1220-03] & JF803254 & \\
\hline ToICV-[BR-PE-Mdc2681-04] & JF803252 & \\
\hline ToLCAnV-[KM-Oua-04] & AM701758 & \\
\hline ToLCArV-[TZ-Kil-05] & EF194760 & \\
\hline ToLCBaV-A[IN-Ban1] & Z48182 & \\
\hline ToLCBaV-[IN-Hes-TC265-10] & KF663698 & \\
\hline ToLCBaV-B[IN-Ban5] & AF295401 & \\
\hline ToLCBaV-C[IN-Ban4-97] & AF165098 & \\
\hline ToLCBaV-D[IN-KerII-05] & DQ852623 & \\
\hline ToLCBV-[BD-BD2] & AF188481 & \\
\hline ToLCCeV-[PH-NuEP2-1-07] & EU487025 & \\
\hline ToLCCNV-BS[CN-Gx32-02] & AJ558118 & \\
\hline ToLCCNV-[CN-Gx-Tob-JX-2-10] & JF681158 & \\
\hline ToLCCNV-NN1[CN-Gx18-02] & AJ558119 & \\
\hline ToLCCNV-NN2[CN-Gx63-03] & AJ704603 & \\
\hline ToLCDiV-[MG-Nam-01] & AM701765 & \\
\hline
\end{tabular}


Table 1 continued

\section{Tomato leaf curl Ghana virus}

Tomato leaf curl Ghana virus - [Ghana-Akumadan-2006]

Tomato leaf curl Ghana virus - Ageratum [Cameroon-AGFG24-2009]

Tomato leaf curl Guangdong virus

Tomato leaf curl Guangdong virus - [China-Guangzhou 2-2003]

Tomato leaf curl Guangxi virus

Tomato leaf curl Guangxi virus - [China-Guangxi 1-2003]

Tomato leaf curl Hainan virus

Tomato leaf curl Hainan virus - [China-FQ12-2012]

Tomato leaf curl Hanoi virus

Tomato leaf curl Hanoi virus - [Vietnam-Hanoi-Tomato-2010]

Tomato leaf curl Hsinchu virus

Tomato leaf curl Hsinchu virus - [China-Hainan-Ramie-2007]

Tomato leaf curl Java virus

Tomato leaf curl Java virus - A [Indonesia]

Tomato leaf curl Java virus - B [Indonesia-Ageratum]

Tomato leaf curl Joydebpur virus

Tomato leaf curl Joydebpur virus - [India-Varanasi-Capsicum annuum-2010]

Tomato leaf curl Kerala virus

Tomato leaf curl Kerala virus - [India-Kerala 3-2007]

Tomato leaf curl Laos virus

Tomato leaf curl Laos virus - [Laos]

Tomato leaf curl Liwa virus

Tomato leaf curl Liwa virus - [Oman-Liwa-LW1-2012]

Tomato leaf curl Madagascar

Tomato leaf curl Madagascar virus - Atsimo [Madagascar-Toliary-2001]

Tomato leaf curl Madagascar virus - Menabe [Madagascar-Morondova-2001]

Tomato leaf curl Malaysia virus

Tomato leaf curl Malaysia virus - Malaysia [Malaysia-Klang-1997]

Tomato leaf curl Mali virus

Tomato leaf curl Mali virus - [Mali]

Tomato leaf curl Mayotte virus

Tomato leaf curl Mayotte virus - [Mayotte-Kahani-2003]

Tomato leaf curl Mayotte virus - Madagascar [Madagascar-Dimadjou-2006]

Tomato leaf curl Mindanao virus

Tomato leaf curl Mindanao virus - [Philippines-Mindanao P162-2007]

Tomato leaf curl New Delhi virus

Tomato leaf curl New Delhi virus - [Bangladesh-Jessore- Severe-2005]

Tomato leaf curl New Delhi virus 2

Tomato leaf curl New Delhi virus 2 - [India-IANDS1-2011]

Tomato leaf curl New Delhi virus 3

Tomato leaf curl New Delhi virus 3 - [India-Bijnor-Chilli-2012]

Tomato leaf curl New Delhi virus 4

Tomato leaf curl New Delhi virus 4 - [India-Junagad-TC306-2011]

Tomato leaf curl Palampur virus

Tomato leaf curl Palampur virus - [India-Palampur-2007]

Tomato leaf curl Patna virus

Tomato leaf curl Patna virus - [India-Patna-2008]

Tomato leaf curl Philippines virus

Tomato leaf curl Philippines virus - A [Philippines-Laguna-2006]

Tomato leaf curl Philippines virus - B [Philippines-Laguna 1-2006]
ToLCGV-[GH-Aku-06]

EU350585

ToLCGV-Ag[CM-AGFG24-09]

FR873228

ToLCGdV-[CN-Gz2-03]

AY602165

ToLCGxV-[CN-Gx1-03]

AM236784

ToLCHaiV-[CN-FQ12-12]

KF150142

ToLCHaV-[VN-Han-tom-10]

HQ162270

ToLCHsV-[CN-Hn-Ram-07]

EU596959

EU596960

ToLCJaV-A[ID]

ToLCJaV-B[ID-Age]

ToLCJV-[IN-Var-Caa-10]

ToLCKeV-[IN-Ker3-07]

EU910141

ToLCLV-[LA]

AF195782

ToLCLwV-[OM-Liw-LW1-12]

HF912280

ToLCMGV-Ats[MG-Tol-01]

ToLCMGV-Men[MG-Mor-01]

AJ865339

AJ865338

ToLCMYV-MY[MY-Kla-97]

AF327436

ToLCMLV-[ML]

AY502936

ToLCYTV-[YT-Kah-03]

AJ865340

ToLCYTV-MG[MG-Dim-06]

AM701761

ToLCMiV-[PH-MinP162-07]

EU487046

ToLCNDV-[BG-Jes-Svr -05]

AJ875157

AJ875158

ToLCNDV2-[IN-IANDS1-11]

JQ897969

ToLCNDV3-[IN-Bij-Chi-12]

KC465466

ToLCNDV4-[IN-Jun-TC306-11]

KF551592

ToLCPalV-[IN-Pal-047]

AM884015

AM992534

ToLCPatV-[IN-Pat-08]

EU862323

ToLCPV-A[PH-Lag-06]

AB377113

ToLCPV-B[PH-Lag1-06] 
Table 1 continued

Tomato leaf curl Philippines virus - C [Philippines-Laguna-2006]

Tomato leaf curl Pune virus

Tomato leaf curl Pune virus - [India-Pune-2005]

Tomato leaf curl Rajasthan virus

Tomato leaf curl Rajasthan virus - [India-Rajasthan-2005]

Tomato leaf curl Seychelles virus

Tomato leaf curl Seychelles virus - [Seychelles-Val d'Endor-2004]

Tomato leaf curl Sinaloa virus

Tomato leaf curl Sinaloa virus - [Nicaragua-Santa Lucia-NI2]

Tomato leaf curl Sri Lanka virus

Tomato leaf curl Sri Lanka virus - [Sri Lanka-Bandarawela-1997]

\section{Tomato leaf curl Sudan virus}

Tomato leaf curl Sudan virus - Gezira [Sudan-Gezira-1996]

Tomato leaf curl Sudan virus - [Sudan-WM-2011]

Tomato leaf curl Sudan virus - Shambat [Sudan-Shambat-1996]

Tomato leaf curl Sudan virus - Yemen [Yemen-2005]

\section{Tomato leaf curl Sulawesi virus}

Tomato leaf curl Sulawesi virus - [Indonesia-Sulawesi-Langowan F101-2006]

\section{Tomato leaf curl Taiwan virus}

Tomato leaf curl Taiwan virus - A [China-Hong Kong T1-2007]

Tomato leaf curl Taiwan virus - [China-NS1-2011]

Tomato leaf curl Taiwan virus - B [Taiwan-Luye 2-4-2009]

Tomato leaf curl Taiwan virus - C [Taiwan-Chiayi-LJC14-2005]

\section{Tomato leaf curl Toliara virus}

Tomato leaf curl Toliara virus - [Madagascar-Miandrivazo-2001]

Tomato leaf curl Uganda virus

Tomato leaf curl Uganda virus - [Uganda-Iganga-2005]

Tomato leaf curl Vietnam virus

Tomato leaf curl Vietnam virus - [Vietnam-Dan Xa 2-2007]

Tomato leaf curl virus

Tomato leaf curl virus - Solanum [Australia-Solanum-D1]

Tomato leaf curl virus - [India-New Delhi-CTS-2006]

Tomato leaf curl virus - Bangalore [India-Punjab-Mentha-2007]

Tomato leaf curl virus - Janti [India-Janti-2005]

Tomato leaf curl virus - Tomato [Australia]

Tomato leaf deformation virus

Tomato leaf deformation virus - [Peru-Tomato-1-2003]

Tomato leaf distortion virus

Tomato leaf distortion virus - [Brazil-Paty do Alferes 4-2005]

Tomato mild mosaic virus

Tomato mild mosaic virus - [Brazil-Paty do Alferes 58-2005]

Tomato mild yellow leaf curl Aragua virus

Tomato mild yellow leaf curl Aragua virus - [Venezuela-10-2003]

Tomato mosaic Havana virus

Tomato mosaic Havana virus - [Cuba-Quivican]

\author{
ToLCPV-C[PH-Lag-06] \\ ToLCPuV-[IN-Pun-05] \\ ToLCRaV-[IN-Raj-05] \\ ToLCSCV-[SC-VE-04] \\ ToLCSiV-[NI-SL] \\ ToLCLKV-[LK-Ban-97] \\ ToLCSDV-Gez[SD-Gez-96] \\ ToLCSDV-[SD-WM-11] \\ ToLCSDV-Sha[SD-Sha-96] \\ ToLCSDV-YE[YE-05]
}

ToLCSuV-[ID-Sul-LanF101-06]

ToLCTV-A[CN-HKT1-07]

ToLCTV-[CN-NS1-11]

ToLCTV-B[TW-Luy2-4-09]

ToLCTV-C[TW-Cy-LJC14-05]

ToLCToV-[MG-Mia-01]

ToLCUV-[UG-Iga-05]

ToLCVV-[VN-DX1-07]

ToLCV-Sol[AU-Sol-D1]

ToLCV-[IN-ND-06]

ToLCV-Ban[IN-Pun-Me-07]

ToLCV-Jan[IN-Jan-05]

ToLCV-To[AU]

ToLDeV-[PE-tom-1-03]

ToLDV-[BR-Pda4-05]

ToMMV-[BR-Pda58-05]

ToMYLCV-[VE-10-03]

ToMHaV-[CU-Qui]

ToMoLCV-[BR-Jai13-08]
AB307731

AY754814

DQ339117

AM491778

AJ608286

AJ508783

AF274349

AY044137

KC763630

AY044139

EF110891

FJ237614

EU624503

JQ867093

GU723730

DQ866128

AM701768

DQ127170

EU189149

AF084006

DQ629101

FJ514798

AY754812

S53251

GQ334472

EU710749

EU710752

EU710753

AY927277

EF547938

Y14874

Y14875

Tomato mottle leaf curl virus

Tomato mottle leaf curl virus - [Brazil-Jaiba 13-2008]

KC706615 
Table 1 continued

Tomato mottle Taino virus

Tomato mottle Taino virus - [Cuba]

Tomato mottle virus

Tomato mottle virus - [United States-Florida-1989]

Tomato mottle wrinkle virus

Tomato mottle wrinkle virus - [Argentina-Pichanal-400-2008]

Tomato rugose mosaic virus

Tomato rugose mosaic virus - [Brazil-Uberlandia 1-1996]

Tomato rugose yellow leaf curl virus

Tomato rugose yellow leaf curl virus - [Uruguay-Salto Grande-U2-2009]

Tomato severe leaf curl virus

Tomato severe leaf curl virus - Guatemala [Guatemala-Sansirisay-1996]

Tomato severe leaf curl virus - [Mexico-Huasteca-2011]

Tomato severe leaf curl virus - Nicaragua [Nicaragua-Condega]

Tomato severe rugose virus

Tomato severe rugose virus - [Brazil-Petrolina de Goias 1-Capsicum-2003]

Tomato yellow leaf curl Axarquia virus

Tomato yellow leaf curl Axarquia virus - [Spain-Algarrobo-ES-mh800-2000]

Tomato yellow leaf curl China virus

Tomato yellow leaf curl China virus - Baoshan1 [China-Yunnan 10-Tobacco-2000]

Tomato yellow leaf curl China virus - [China-Yunnan 25-Tomato-2000]

Tomato yellow leaf curl China virus - Baoshan3 [China-Yunnan 278-Malvastrum2007]

Tomato yellow leaf curl China virus - Bean [China-Yunnan-Bean-2004]

Tomato yellow leaf curl China virus - Dali [China-Yunnan 5-Tobacco-1999]

Tomato yellow leaf curl China virus - Datura [China-Yunnan 72- Datura -2005]

Tomato yellow leaf curl China virus - Honghe [China-Guangxi]

Tomato yellow leaf curl Indonesia virus

Tomato yellow leaf curl Indonesia virus - [Indonesia-Lembang-2005]

Tomato yellow leaf curl Kanchanaburi virus

Tomato yellow leaf curl Kanchanaburi virus - [Thailand-Kanchanaburi 1-2001]

Tomato yellow leaf curl Malaga virus

Tomato yellow leaf curl Malaga virus - [Spain-421-1999]

Tomato yellow leaf curl Mali virus

Tomato yellow leaf curl Mali virus - Ethiopia [Ethiopia-Melkassa-2005]

Tomato yellow leaf curl Mali virus - Mali [Mali -2003]

Tomato yellow leaf curl Sardinia virus

Tomato yellow leaf curl Sardinia virus - [Italy-Sardinia-1988]

Tomato yellow leaf curl Thailand virus

Tomato yellow leaf curl Thailand virus - A [Thailand-1]

Tomato yellow leaf curl Thailand virus - B [Thailand-Chiang Mai]

Tomato yellow leaf curl Thailand virus - C [China-Yunnan 72-2002]

Tomato yellow leaf curl Thailand virus - D [Myanmar-Yangon-1999]

Tomato yellow leaf curl Thailand virus - E [Thailand-Sakon Nakhon]

Tomato yellow leaf curl virus

Tomato yellow leaf curl virus - [Israel-Rehovot-1986]

Tomato yellow leaf curl virus - Boushehr [Iran- Genaveh 29-2006]

Tomato yellow leaf curl virus - Iran [Iran-Iranshahr-1998]

Tomato yellow leaf curl virus - Kahnoo [Iran-Kahnooj-2007]

Tomato yellow leaf curl virus - Kerman [Iran-Hormozgan 32-2006]
ToMoTaV-[CU]

AF012300

AF012301

ToMoV-[US-Flo-89]

L14460

L14461

ToMoWV-[AR-Pic-400-08]

JQ714137

ToRMV-[BR-Ube1-96]

AF291705

AF291706

TRYLCV-[UY-SG-U2-09]

JN381819

ToSLCV-GT[GT-San-96]

AF130415

ToSLCV-[MX-Hua-11]

JN680352

ToSLCV-NI[NI-Con]

AJ508784

ToSRV-[BR-PG1-Cap-03]

DQ207749

TYLCAxV-[ES-Alg-ES-mh800-00]

AY227892

TYLCCNV-BS1[CN-Yn10-Tob 00]

TYLCCNV-[CN-Yn25-Tom-00]

AJ319675

TYLCCNV-BS3[CN-Yn278-Mal07]

TYLCCNV-Bea[CN-Yn-Bea-04]

TYLCCNV-DL[CN-Yn5-Tob-99]

TYLCCNV-Dat[CN-Yn72-Dat-05]

TYLCCNV-HH[CN-Gx]

TYLCIDV-[ID-Lem-05]

TYLCKaV-[TH-Kan1-01]

AF511529

AF511528

TYLCMaV-[ES-421-99]

AF271234

TYLCMLV-ET[ET-Mel-05]

DQ358913

TYLCMLV-ML[ML-03]

TYLCSV-[IT-Sar-88]

X61153

TYLCTHV-A[TH-1]

X63015

X63016

TYLCTHV-B[TH-ChMai]

TYLCTHV-C[CN-Yn72-02]

TYLCTHV-D[MY-Yan-99]

AY514630

AY514633

AJ495812

AF206674

TYLCTHV-E[TH-SaNa]

AY514632

AY 514635

TYLCV-[IL-Reo-86]

X15656

TYLCV-Bou[IR-Gen29-06]

GU076454

TYLCV-IR[IR-Ira-98]

AJ132711

TYLCV-Kah[IR-Kah-07]

EU635776

TYLCV-Ker[IR-Hor32-06]

GU076442 
Table 1 continued

\begin{tabular}{|c|c|c|c|}
\hline Tomato yellow leaf curl virus - Mild [Israel-1993] & TYLCV-Mld[IL-93] & X76319 & \\
\hline Tomato yellow leaf curl virus - Oman [Oman-Al-batinah 22-2005] & TYLCV-OM[OM-Alb22-05] & FJ956700 & \\
\hline \multicolumn{4}{|l|}{ Tomato yellow leaf curl Yunnan virus } \\
\hline Tomato yellow leaf curl Yunnan virus - [China-YN2013-2011] & TYLCYnV-[CN-YN2013-11] & КC686705 & \\
\hline \multicolumn{4}{|l|}{ Tomato yellow leaf distortion virus } \\
\hline Tomato yellow leaf distortion virus - [Cuba-5E17-2007] & ToYLDV-[CU-5E17-07] & FJ174698 & \\
\hline \multicolumn{4}{|l|}{ Tomato yellow margin leaf curl virus } \\
\hline Tomato yellow margin leaf curl virus - [Venezuela-Merida-57] & ToYMLCV-[VE-Mer-57] & AY508993 & \\
\hline \multicolumn{4}{|l|}{ Tomato yellow mottle virus } \\
\hline Tomato yellow mottle virus - [Costa Rica-2003] & ToYMoV-[CR-03] & KC176780 & \\
\hline \multicolumn{4}{|l|}{ Tomato yellow spot virus } \\
\hline Tomato yellow spot virus - [Brazil-Bicas 2-1999] & ToYSV-[BR-Bic2-99] & DQ336350 & DQ336351 \\
\hline Tomato yellow spot virus - Leonurus [Brazil-PR49-2007] & ToYSV-Le[BR-PR49-07] & JX863081 & \\
\hline \multicolumn{4}{|l|}{ Tomato yellow vein streak virus } \\
\hline Tomato yellow vein streak virus - [Brazil-Potato-1983] & ToYVSV-[BR-Pot-83] & EF417915 & EF417916 \\
\hline \multicolumn{4}{|l|}{ Velvet bean severe mosaic virus } \\
\hline Velvet bean severe mosaic virus - [India-Lucknow-2008] & VBSMV-[IN-Luc-08] & FN543425 & FN543426 \\
\hline \multicolumn{4}{|l|}{ Vernonia yellow vein Fujian virus } \\
\hline Vernonia yellow vein Fujian virus - [China-Fujian-2009] & VeYVFV-[CN-Fj-09] & JF265670 & \\
\hline \multicolumn{4}{|l|}{ Vernonia yellow vein virus } \\
\hline Vernonia yellow vein virus - [India-Madurai-2005] & VeYVV-[IN-Mad-05] & AM182232 & \\
\hline \multicolumn{4}{|l|}{ Vigna yellow mosaic virus } \\
\hline Vigna yellow mosaic virus - [Mexico-Morelos-Yautepec-2007] & ViYMV-[MX-Mor-Yau-07] & KC430936 & \\
\hline \multicolumn{4}{|l|}{ Watermelon chlorotic stunt virus } \\
\hline Watermelon chlorotic stunt virus - [Iran-1997] & WmCSV-[IR-97] & AJ245652 & $\mathrm{AJ} 245653$ \\
\hline \multicolumn{4}{|l|}{ West African Asystasia virus 1} \\
\hline West African Asystasia virus 1 - [West Africa-Asystasia1-2011] & WAAV1-[WA-Asy1-11] & JF694486 & \\
\hline \multicolumn{4}{|l|}{ West African Asystasia virus 2} \\
\hline West African Asystasia virus 2 - [West Africa-Asystasia2-2011] & WAAV2-[WA-Asy2-11] & JF694484 & \\
\hline \multicolumn{4}{|l|}{ Wissadula golden mosaic virus } \\
\hline Wissadula golden mosaic virus - [Jamaica-St Thomas-2005] & WGMV-[JM-StT-05] & DQ395343 & EU158095 \\
\hline
\end{tabular}

The most obvious benefit to using the SDT-based pairwise identity analysis is that there are fewer species and strains at the interface between the cutoff and the next lower or higher percent nt sequence identity. As such, applying the proposed $91 \%$ cutoff increases reliability owing to the robust stringency.

\section{Why so many begomoviruses?}

As noted above, the genus Begomovirus includes the largest number of species of all currently established genera, with 288 species currently recognized by the ICTV. Why so many begomoviruses? Are these species "artificial", the result of flawed taxonomic demarcation criteria? The existence of this large number of species can be explained by natural order relationships based on the characteristics of this genus that set it apart from many other viral genera.
Begomoviruses are transmitted by members of a cryptic species complex, Bemisia tabaci (Genn.) (Hemiptera: Aleyrodidae), which is distributed worldwide and colonize a wide array of plants belonging to species in many families [22-25]. B. tabaci has emerged as a major threat to agricultural systems in many regions of the world since the 1970s and 1980s [26, 27]. Reports of unprecedented $B$. tabaci infestations have characteristically resulted in outbreaks of previously undescribed begomoviruses and the apparent disappearance of others from cultivated plants [28]. Because B. tabaci colonizes so many plant species [25], it potentiates the transfer of begomoviruses between non-cultivated and cultivated hosts (which are most studied by plant virologists). While it is beyond the scope of this proposal to fully explore the hypothesis that most begomoviruses isolated from cultivated hosts likely evolved from viruses originally adapted to infecting non-cultivated 
A

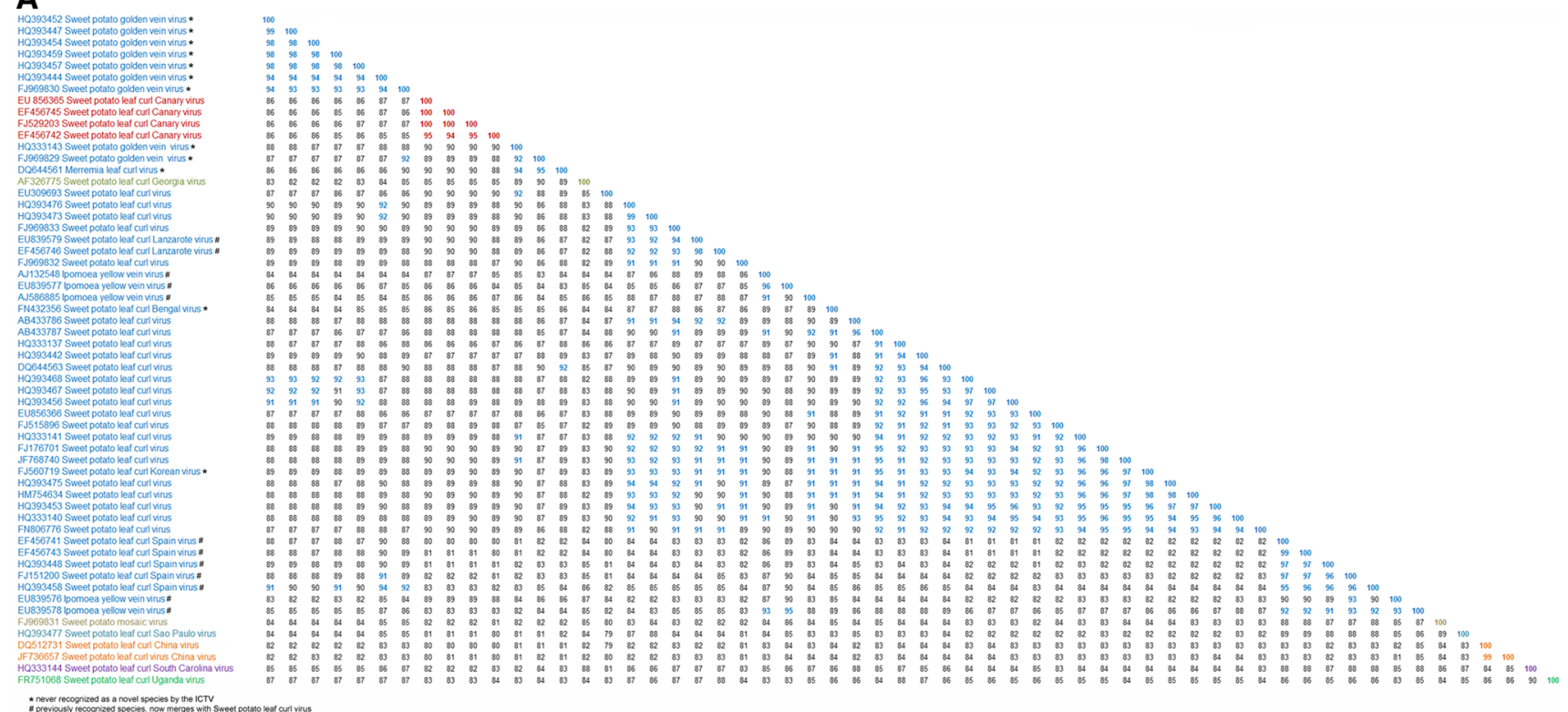

Fig. 1 (A) Pairwise sequence comparisons and (B) maximumlikelihood phylogenetic tree of sequences comprising the "sweepovirus" group. Sequences corresponding to the same species based on

hosts, this hypothesis could explain, at least in part, why there are so many more begomovirus species than are found for other virus genera where virus-host-vector interactions are more evolutionarily ancient.

Another consideration is that virologists working with ssDNA viruses have gained a powerful new tool in the form of rolling circle-amplification (RCA), a method that allows for rapid, sequence-independent sampling of virus populations. The impact of RCA in the field of geminivirology cannot be overstated (for example, see ref. [29]). Using RCA, it is possible to amplify and recover the complete genome of almost any begomovirus from minute amounts of total plant DNA extracted under suboptimal conditions [30]. Presently, tissue samples can be collected, dried, and stored for months or years at room temperature, and thousands of complete begomovirus genomes will be readily amplified using RCA following a quick DNA extraction [31, 32]. In the 1990s it would take months to clone one full-length begomovirus genome, whereas hundreds of genomes can now be cloned in a matter of weeks. Furthermore (and equally relevant), because RCA uses random primers, it reduces sequence amplification biases and enables the detection of most or all unique genome molecules present in a sample. As a result, new begomoviruses and other, often highly divergent, geminiviruses have been discovered that will probably lead to the recognition of additional genera in the family (and perhaps new families as well) [33-36]. Also, this new technology has prompted a significant increase in the numbers of novel a $91 \%$ cutoff (using the parameters described in the main text) are highlighted in the same color

begomoviruses that are being sought, and found, in noncultivated plants.

Finally, it should be pointed out that the extent of diversity currently recognized within this genus (and possibly for all viruses) represents only the tip of the iceberg. Metagenomic approaches are rapidly becoming affordable and will probably lead to the discovery of viruses belonging to hundreds of new genera and families, not to mention species [37]. Its impact on geminivirus discovery has already been felt [38-42].

\section{Different cutoff values must be used for the different genera in the family Geminiviridae}

The approach implemented herein to demarcate species in the genus Begomovirus is identical to that used and approved by the ICTV for the other genera in the family [12, $13,36]$. However, for each genus, the working cutoff for species demarcation differs, even though the method applied to determine these cutoffs has been the same. For example, mastrevirus species are demarcated using a $78 \%$ cutoff. The $78 \%$ species cutoff value for the mastreviruses is demonstrated by the pairwise distance distribution plot (Fig. 2A), in which a clear valley is apparent at $78 \%$. Such a valley is not readily evident in the equivalent plot for the begomoviruses (Fig. 2B and C), leading us to analyze this genus using groups of sequences. The analysis reported herein supported a $91 \%$ cutoff value for begomoviruses as 
Fig. 1 continued
B

92:Sweet potato leaf curl Canary virus EU856365

$\infty$ sweet potato leaf curl Canaryvinus EF450745

Sweet potato leaf curl Canary virus FJ529203

-sweet potato leaf curl Canary virus EF 456742

sweet potato goldenvein virus FJ969829*

sweet potato leaf curl virus DQ644561*

-sweet potato leaf curlvirus EU 309693

sweet potato leaf curl virus FJ 969832

sweet potato leaf curl virus SPLCV HQ393473

[sweet potato leaf curl virus SPLCV HQ393476

53 sweet potato leaf curl virus FJ 969833

34 sweet potato leaf curl Lanzarote virus EF456746 \#

100 sweet potato leaf curl Lanzarote virus EU839579\#

sweet potato leaf curl Bengal virus FN432356 *

56 ipomoea yellowvein virus A.J132548\#

Sweet potato leaf curlvirus AB433787

veet potato leaf curl virus AB433786

sweet potato leaf curl virus HQ393468

74

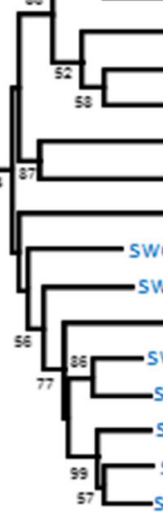

sweet potato leaf curlvirus DQ644563

sweet potato leaf curl virus HQ393442

sweet potato leaf curl virus HQ333137

- sweet potato leaf curlvirus FJ515896

sweet potato leaf curl virus EU856366

sweet potato leaf curl virus FN806776

sweet potato leaf curl virus HQ333140

sweet potato leaf curl virus HQ393453

sweet potato leaf curl virus HQ333141

weet potato leaf curl virus JF768740

weet potato leaf curl virus FJ176701

sweet potato leaf curl virus HM754634

- sweet potato leaf curlvirus HQ393475

sweet potato leaf curl Korean virus FJ560719*

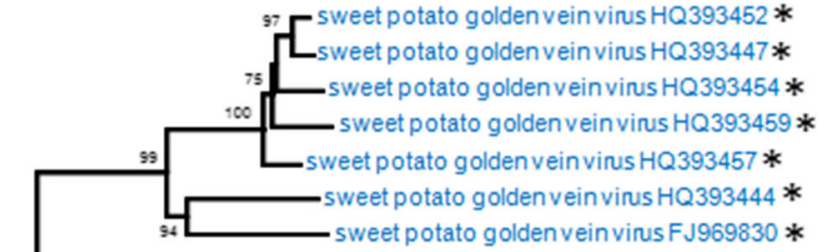
sweet potato leaf curl Spain virus HQ393448 \#

$\stackrel{10.02}{1}$

* never recognized as a member of a novel species by the ICTV

\# previously recognized species, now merges with sweet potato leaf curl virus 
Fig. 2 Distribution of the fullgenome pairwise sequence identity scores for members of the genera (A)Mastrevirus and (B, C)Begomovirus

(C corresponds to a higher resolution of the shaded region in B). Note the valley (or gap) corresponding to the 72-78\% frequencies in the Mastrevirus plot and the absence of significant valleys in the Begomovirus plot
A

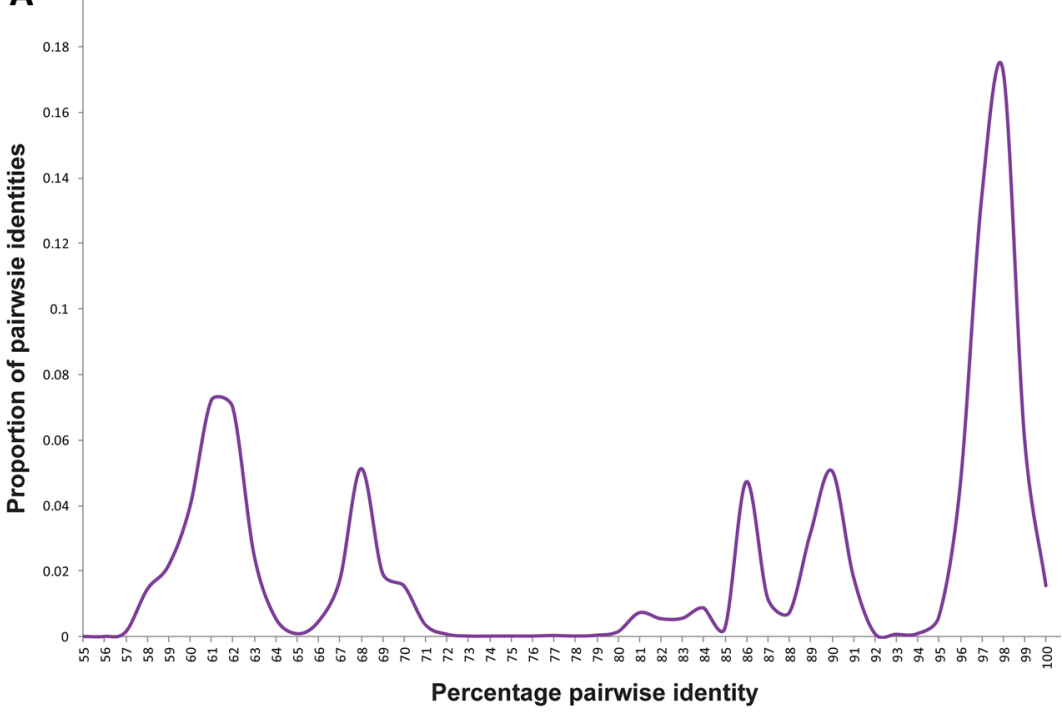

B

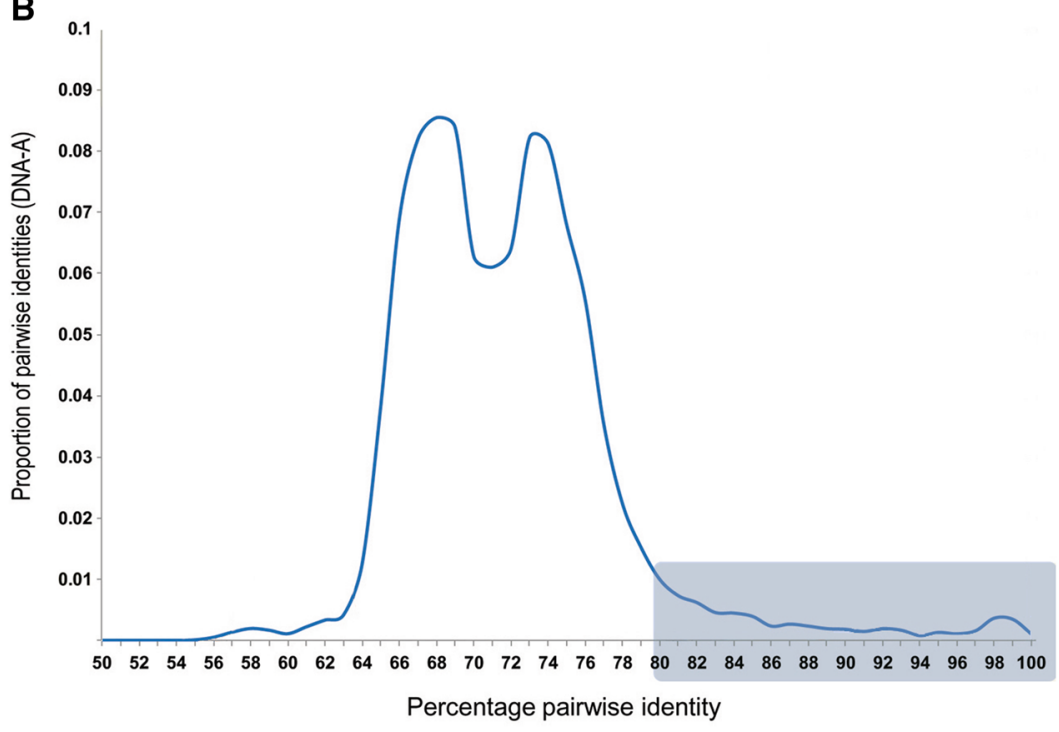

C ${ }_{0.012}$

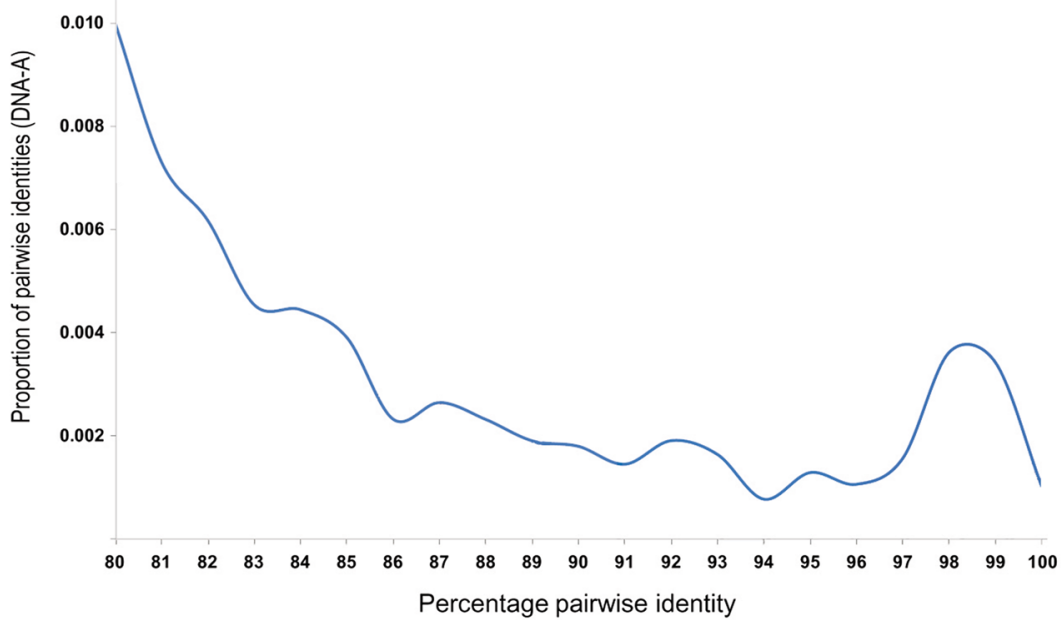


that which best separates the species in the genus, and this is well supported by the SDT analysis.

Several other families and genera have species demarcation thresholds similar to that of the begomoviruses, including Parvovirus (95\%), Microviridae (80-85\%) and Sobemovirus (60-85\%). It is perhaps troubling that a uniform approach for computing species thresholds does not exist across all of viral taxonomy at this time. Currently, various study groups use different algorithms for specific genes, sets of genes, or complete genomes. Further, complete genome sequences are lacking for viruses of many species, particularly those with large genomes. In those instances, the trees represent a gene tree instead of a virus tree, which can create misconceptions about viral genome structure and lead to incorrect evolutionary inferences. It will be interesting to see if our approach may be useful for other viral families.

\section{A step-by-step guide for classifying new begomovirus isolates as members of species or strains}

To facilitate the taxonomic placement of newly discovered begomoviruses and to assist in the standardization of this procedure, the following guidelines are proposed for classification into species and strains:

1. A BLASTn analysis of the "non-redundant nucleotide" database should be performed to identify the species whose members have sequences most similar to the new sequence. The nucleotide sequence database at the NCBI website (http://www.ncbi.nlm. nih.gov/nuccore/) can also be searched using the search term "txid10814 [Organism: exp] AND 2500:3500[SLEN]", which will return all begomovirus nucleotide sequences that are between 2500 and 3500 nucleotides long.

2. The new sequence should be added to a dataset of fulllength genomes or DNA-A components created based on the BLAST results, and saved in FASTA format. All sequences must start at the same genomic coordinate (the first nucleotide after the nicking site within the conserved nonanucleotide at the origin of replication is the recommended standard).

3. The MUSCLE option in SDT v1.2 (freely available at http://www.cbio.uct.ac.za/SDT) or any other program that uses the MUSCLE alignment algorithm with pairwise deletion of gaps should be used to calculate identities between every pair of sequences in the dataset. If using SDT, these pairwise identities may be saved in either a column or matrix csv format that can then be viewed in a spreadsheet program such as
Microsoft Excel. Percent identities must be rounded to the nearest full percentile.

4. If the new sequence shares $<91 \%$ genome-wide pairwise identity to any other known begomovirus sequence, appropriate species and virus names should then be proposed (see below for guidelines on doing so).

5. If the sequence shares $<94 \%$ genome-wide pairwise identity to all isolates described for that species, a strain name should then be proposed.

\section{Guidelines for naming new species that include newly discovered begomoviruses}

\section{Virus species name}

This is the ICTV-accepted name of a group of begomoviruses sharing $\geq 91 \%$ pairwise sequence identity for the full-length genome or DNA-A component. If the sequence has $<91 \%$ sequence identity to all begomoviruses previously classified as members of distinct species, the virus should be considered a member of a new species, and a unique name that is not currently in use for any ICTVrecognized species should be assigned. This name should follow the template "Host symptom virus" (e.g., Bean golden mosaic virus). Although it was common practice for begomoviruses, the Geminiviridae SG recommends that country, city, town, village or province names not be used in naming new viruses and new viral species (e.g., Tomato yellow leaf curl Thailand virus), as this may cause misunderstandings when a virus named after a country or city is subsequently found in other locations within that country or in other countries. (Previously accepted names using this practice will not be changed to avoid conflicts in the literature.)

\section{Strain name}

Based on ICTV guidelines, there is no practical or standardized approach for differentiating or naming strains (or any other category below the species level). In fact, item 3.3 of the ICTV Statutes states that "The ICTV is not responsible for classification and nomenclature of virus taxa below the rank of species." Nevertheless, the Geminiviridae Study Group has adopted its own guidelines for strain differentiation and nomenclature [43], although there is no formal requirement to do so. Our new analysis indicated a sequence identity threshold of $94 \%$ for strain demarcation.

Ideally (when knowledge is available), strains should follow a nomenclature that reflects biological differences 
between the members of the same species. For example, if it is established that a number of BGMV isolates comprising a distinct strain are capable of infecting a host (e.g., lima bean) that other BGMV isolates do not normally infect, it would then be appropriate to name the strain BGMV-Lima bean. Likewise, symptom severity descriptors (e.g., Tomato golden mosaic virus-Yellow vein) could also be used. In either case, such strain names should be used only when the phenotype is observed in multiple isolates of the same strain. As recommended for species names, country, city, town, village or province names should not be used in naming new strains. Strain name follows species name separated by a hyphen ("-").

\section{Isolate descriptor}

Following the species/strain name, and within square brackets ("[ ]"), the isolate descriptor may contain any number of subfields separated by hyphens. Although the 9th ICTV Report's recommendations for geminivirus nomenclature [1] suggested the use of colons (":") to separate sub-fields in the isolate descriptor, this can cause problems in various phylogenetic-tree-drawing programs, which, when reading phylogenetic trees in Newick format, will misinterpret numbers after the colon as representing branch length information.

The first sub-field should always be the two-letter international code of the country/territory in which the isolate was sampled (Supplementary Table S2), whereas the last sub-field should always be the year in which the isolate was last present within living tissue. If the year in which the isolate was sampled differs from the date on which it was last present within living tissue (e.g., when isolates are propagated in the laboratory), the date when the isolate was sampled should then be included as an internal sub-field. Between the first and last sub-fields, any additional descriptors can be used (for example, the laboratory code of the sample from which the isolate was obtained, the city nearest to the place where the sample was obtained, the host species from which the virus was isolated).

\section{Conclusions}

Since the 1990s begomovirus taxonomy has been based primarily on sequence comparisons methods. In this regard, it was pioneering, helped by the large number of full-length sequences available, and allowed for a robust statistical treatment of the data. Although this approach has been criticized for not taking biology into account, a closer look into the recognized species will show that biology is accurately reflected in the taxonomy. This revision demonstrated the robustness and the reliability of a sequence-based taxonomy, and this was acknowledged by the ICTV with the positive outcome of the latest taxonomy proposal and the establishment of new begomovirus species (http://talk.ictvonline.org/ files/ictv_official_taxonomy_updates_since_the_8th_report/ $\mathrm{m} /$ plant-official/4838.aspx). It should be noted, however, that the ICTV Geminiviridae SG has no ulterior motivation for continuing to propose new species. Rather, the number of new species proposed is a genuine reflection of our increasingly effective methods to conceptualize the natural genetic variability of this remarkable group of viruses. By establishing clear guidelines for the analysis of full-length genomic sequences, and following standardized nomenclature for the naming of newly established species and strains, the intention of the ICTV Geminiviridae SG is that these changes will improve taxonomic communications among users while also leaving open options for further improvements in the future that will serve the geminivirus community at large.

Acknowledgments The analysis described in this manuscript was part of the taxonomic proposal 2013.015a,bP, approved by the Executive Committee of the ICTV in July 2013 and ratified in March 2014. JKB and FMZ are past and current chairs, respectively, of the Geminiviridae Study Group of the ICTV. JNC, EM, RWB, CHZ, AI, VGM, DPM, RRB, SU and AV were members of the Geminiviridae SG during 2012-2014, when the work was performed. JNC and EM are members of the Research Group AGR-214, partially funded by Consejería de Economía, Innovación y Ciencia, Junta de Andalucía, Spain, cofinanced by FEDER-FSE. DPM and AV are supported by the National Research Foundation of South Africa.

\section{References}

1. Brown JK, Fauquet CM, Briddon RW, Zerbini FM, Moriones E, Navas-Castillo J (2012) Family Geminiviridae. In: King AMQ, Adams MJ, Carstens EB, Lefkowitz EJ (eds) Virus taxonomy. Ninth report of the international committee on taxonomy of viruses. Elsevier Academic Press, London, pp 351-373

2. Sanchez-Campos S, Martinez-Ayala A, Marquez-Martin B, Aragon-Caballero L, Navas-Castillo J, Moriones E (2013) Fulfilling Koch's postulates confirms the monopartite nature of tomato leaf deformation virus: a begomovirus native to the New World. Virus Res 173:286-293

3. Melgarejo TA, Kon T, Rojas MR, Paz-Carrasco L, Zerbini FM, Gilbertson RL (2013) Characterization of a new world monopartite begomovirus causing leaf curl disease of tomato in Ecuador and Peru reveals a new direction in geminivirus evolution. J Virol 87:5397-5413

4. Nakhla MK, Maxwell DP, Martinez RT, Carvalho MG, Gilbertson RL (1994) Widespread occurrence of eastern Mediterranean "strain" of tomato yellow leaf curl geminivirus in tomatoes in the Dominican Republic. Plant Dis 78:926

5. Duffy S, Holmes EC (2007) Multiple introductions of the old world begomovirus Tomato yellow leaf curl virus into the new world. Appl Environ Microb 73:7114-7117

6. Zhang W, Olson NH, Baker TS, Faulkner L, Agbandje-McKenna M, Boulton MI, Davies JW, McKenna R (2001) Structure of the Maize streak virus geminate particle. Virology 279:471-477

7. Stanley J, Gay MR (1983) Nucleotide sequence of cassava latent virus DNA. Nature 301:260-262 
8. Hamilton WD, Stein VE, Coutts RHA, Buck KW (1984) Complete nucleotide sequence of the infectious cloned DNA components of tomato golden mosaic virus: potential coding regions and regulatory sequences. EMBO J 3:2197-2205

9. Harrison BD (1985) Advances in geminivirus research. Annu Rev Phytopathol 23:55-82

10. Padidam M, Beachy RN, Fauquet CM (1995) Classification and identification of geminiviruses using sequence comparisons. J Gen Virol 76:249-263

11. Van Regenmortel $\mathrm{MH}$, Ackermann HW, Calisher $\mathrm{CH}$, Dietzgen RG, Horzinek MC, Keil GM, Mahy BW, Martelli GP, Murphy FA, Pringle C, Rima BK, Skern T, Vetten HJ, Weaver SC (2013) Virus species polemics: 14 senior virologists oppose a proposed change to the ICTV definition of virus species. Arch Virol 158:1115-1119

12. Muhire B, Martin DP, Brown JK, Navas-Castillo J, Moriones E, Zerbini FM, Rivera-Bustamante R, Malathi VG, Briddon RW, Varsani A (2013) A genome-wide pairwise-identity-based proposal for the classification of viruses in the genus Mastrevirus (family Geminiviridae). Arch Virol 158:1411-1424

13. Varsani A, Martin DP, Navas-Castillo J, Moriones E, HernandezZepeda C, Idris A, Zerbini FM, Brown JK (2014) Revisiting the classification of curtoviruses based on genome-wide pairwise identity. Arch Virol 159:1873-1882

14. Muhire BM, Varsani A, Martin DP (2014) SDT: a virus classification tool based on pairwise sequence alignment and identity calculation. PLOS One 9:e108277

15. Edgar RC (2004) MUSCLE: a multiple sequence alignment method with reduced time and space complexity. BMC Bioinform 5:1-19

16. Tamura K, Peterson D, Peterson N, Stecher G, Nei M, Kumar S (2011) MEGA5: molecular evolutionary genetics analysis using maximum likelihood, evolutionary distance, and maximum parsimony methods. Mol Biol Evol 28:2731-2739

17. Albuquerque LC, Inoue-Nagata AK, Pinheiro B, Resende RO, Moriones E, Navas-Castillo J (2012) Genetic diversity and recombination analysis of sweepoviruses from Brazil. Virol J 9:241

18. Morales FJ, Jones PG (2004) The ecology and epidemiology of whitefly-transmitted viruses in Latin America. Virus Res 100:57-65

19. Gilbertson RL, Faria JC, Ahlquist P, Maxwell DP (1993) Genetic diversity in geminiviruses causing bean golden mosaic disease: the nucleotide sequence of the infectious cloned DNA components of a Brazilian isolate of bean golden mosaic geminivirus. Phytopathology 83:709-715

20. Gilbertson RL, Hidayat SH, Martinez RT, Leong SA, Faria JC, Morales FJ, Maxwell DP (1991) Differentiation of bean-infecting geminiviruses by nucleic acid hybridization probes and aspects of bean golden mosaic in Brazil. Plant Dis 75:336-342

21. Morra MR, Petty ITD (2000) Tissue specificity of geminivirus infection is genetically determined. Plant Cell 12:2259-2270

22. Brown JK, Frohlich DR, Rosell RC (1995) The sweetpotato or silverleaf whiteflies: biotypes of Bemisia tabaci or a species complex? Annu Rev Entomol 40:511-534

23. De Barro PJ, Liu SS, Boykin LM, Dinsdale AB (2011) Bemisia tabaci: a statement of species status. Annu Rev Entomol 56:1-19

24. Brown JK (2010) Phylogenetic biology of the Bemisia tabaci sibling species group. In: Stansly PA, Naranjo SE (eds) Bemisia: bionomics and management of a global pest. Springer, Dordrecht, pp 31-67

25. Gill R, Brown JK (2010) Systematics of Bemisia and Bemisia relatives: can molecular techniques solve the Bemisia tabaci complex conundrum-a taxonomist's viewpoint. In: Stansly PA, Naranjo SE (eds) Bemisia: bionomics and management of a global pest. Springer, Dordrecht, pp 5-29

26. Brown JK, Bird J (1992) Whitefly-transmitted geminiviruses and associated disorders in the Americas and the Caribbean basin. Plant Dis 76:220-225
27. Costa AS (1975) Increase in the populational density of Bemisia tabaci, a threat to widespread virus infection of legume crops in Brazil. In: Bird J, Maramorosch K (eds) Tropical diseases of legumes. Academic Press, New York, p 171

28. Brown JK (2007) The Bemisia tabaci complex: genetic and phenotypic variability drives begomovirus spread and virus diversification. APSNet Featur. doi:10.1094/APSnetFeature-20070107

29. Haible D, Kober S, Jeske H (2006) Rolling circle amplification revolutionizes diagnosis and genomics of geminiviruses. J Virol Methods 135:9-16

30. Owor BE, Shepherd DN, Taylor NJ, Edema R, Monjane AL, Thomson JA, Martin DP, Varsani A (2007) Successful application of FTA Classic Card technology and use of bacteriophage phi29 DNA polymerase for large-scale field sampling and cloning of complete maize streak virus genomes. J Virol Methods 140:100-105

31. Inoue-Nagata AK, Albuquerque LC, Rocha WB, Nagata T (2004) A simple method for cloning the complete begomovirus genome using the bacteriophage phi29 DNA polymerase. J Virol Methods 116:209-211

32. Shepherd DN, Martin DP, Lefeuvre P, Monjane AL, Owor BE, Rybicki EP, Varsani A (2008) A protocol for the rapid isolation of full geminivirus genomes from dried plant tissue. J Virol Methods 149:97-102

33. Krenz B, Thompson JR, Fuchs M, Perry KL (2012) Complete genome sequence of a new circular DNA virus from grapevine. J Virol 86:7715

34. Loconsole G, Saldarelli P, Doddapaneni H, Savino V, Martelli GP, Saponari M (2012) Identification of a single-stranded DNA virus associated with citrus chlorotic dwarf disease, a new member in the family Geminiviridae. Virology 432:162-172

35. Bernardo P, Golden M, Akram M, Naimuddin Nadarajan N, Fernandez E, Granier M, Rebelo AG, Peterschmitt M, Martin DP, Roumagnac P (2013) Identification and characterisation of a highly divergent geminivirus: evolutionary and taxonomic implications. Virus Res 177:35-45

36. Varsani A, Navas-Castillo J, Moriones E, Hernández-Zepeda C, Idris A, Brown JK, Zerbini FM, Martin DP (2014) Establishment of three new genera in the family Geminiviridae: Becurtovirus, Eragrovirus and Turncurtovirus. Arch Virol 159:2193-2203

37. Edwards RA, Rohwer F (2005) Viral metagenomics. Nat Rev Microbiol 3:504-510

38. Ng TFF, Duffy S, Polston JE, Bixby E, Vallad GE, Breitbart M (2011) Exploring the diversity of plant DNA viruses and their satellites using vector-enabled metagenomics on whiteflies. PLOS One 6:e19050

39. Idris A, Al-Saleh M, Piatek MJ, Al-Shahwan I, Ali S, Brown JK (2014) Viral metagenomics: analysis of begomoviruses by Illumina high-throughput sequencing. Viruses 6:1219-1236

40. Candresse T, Filloux D, Muhire B, Julian C, Galzi S, Fort G, Bernardo P, Daugrois JH, Fernandez E, Martin DP, Varsani A, Roumagnac P (2014) Appearances can be deceptive: revealing a hidden viral infection with deep sequencing in a plant quarantine context. PLOS One 9:e102945

41. Rosario K, Duffy S, Breitbart M (2012) A field guide to eukaryotic circular single-stranded DNA viruses: insights gained from metagenomics. Arch Virol 157:1851-1871

42. Rosario K, Breitbart M (2011) Exploring the viral world through metagenomics. Curr Opin Virol 1:289-297

43. Fauquet CM, Briddon RW, Brown JK, Moriones E, Stanley J, Zerbini FM, Zhou X (2008) Geminivirus strain demarcation and nomenclature. Arch Virol 153:783-821 